\title{
Characterization of sequential dual-curing of thiol-acrylate-epoxy systems with controlled thermal properties
}

Claudio Russo ${ }^{1}$, Àngels Serra ${ }^{2}$, Xavier Fernández-Francos ${ }^{3}$, Silvia De la Flor ${ }^{1}$.

${ }^{1}$ Department of Mechanical Engineering, Universitat Rovira i Virgili, Av. Països Catalans 26, 43007

Tarragona, Spain

${ }^{2}$ Department of Analytical and Organic Chemistry, Universitat Rovira i Virgili, C/Marcel·lí Domingo

s/n, 43007, Tarragona, Spain;

${ }^{3}$ ThermodynamicsLaboratory, ETSEIB, Universitat Politècnica de Catalunya, Av. Diagonal 647, 08028

Barcelona, Spain

*Correspondence: xavier.fernandez@mmt.upc.edu; Tel.: +34-934017955

\begin{abstract}
In this work, a novel sequential dual-curing system based on thiol-acrylate-epoxy formulations is developed and characterized. Both reaction stages are thermally activated and sequentially relies on difference in the kinetics of the reactions involved. The viability of this system is successfully tested for low curing temperatures and the kinetic of the entire process is completely characterized. Differential scanning calorimetry and Fourier transform infrared spectroscopy analysis revealed an adequate separation between the reactions that leads to a wide interval of time during which the intermediate material can be considered stable. Applicability tests on the resulting thermosets showed the high capability of the intermediate materials to be conformed in complex shapes that can be fixed by means of the second curing stage. This system also shows great potential to be used as adhesive bonding taking advantage of the two-step curing process.
\end{abstract}

\section{Keywords}

Dual-curing; click-chemistry; thiol; acrylate; epoxy; functional material;

\section{INTRODUCTION}

Nowadays thermosets cover a broad range of applications thanks to their excellent thermal and mechanical properties (i.e. aviation, automobile, structures or coatings) [1]. Their properties rely on a crosslinked network structure formed during an irreversible curing process that has to be strictly controlled in order to obtain the required shapes and properties. The increasing need to reach complex shape designs [2] to spread the fields of application (i.e. bio-inspired devices or shape-changing materials) is driving the scientific 
community to experimenting with new curing techniques, which allows to overcome thermosets limitations in shape [3].

Over the last few years, dual-curing polymer systems have attracted a growing interest because of the enhancement they provide in thermosets processing. A dual-curing process is defined as a combination of two distinct crosslinking reactions taking place simultaneously or sequentially [4]. Combining two sequential curing reactions, we obtain intermediate materials that maintain the ability to react upon application of a second stimulus, achieving fully cured materials with a new set of properties. Sequential dual-curing facilitates ease in processing and handling if the intermediate materials are chemically stable and their properties tailorable. Successful sequential dual-curing procedure requires that (i) both polymerization reactions are selective and compatible in order to avoid undesired reactivity effects and inhibition; (ii) they can be triggered by different external stimuli such as UV light or temperature, or else they can be controlled from a kinetics point of view.

To obtain such system, multiple approaches and a large variety of reactions are possible. "Click chemistry" defines a class of reactions with some characteristics, such as high efficiency, versatility and selectivity [5-7], which represent a valuable tool for sequential dual-curing. Among them, thiol-click reaction has attracted great interest due to their advantages (high conversion, solvent-free, oxygen resistance, etc.) [8-10] which makes them suitable to prepare crosslinked polymers in a fast and efficient way.

Michael-type additions, also included in the group of click reactions, are widely used in dual curing processes, because of the variety of commercially available nucleophiles (Michael donors) and activated double bond compounds (Michael acceptors) that can be used in such processes. Prominent Michael acceptors are acrylates because of a good combination of reactivity, versatility, availability and cost. One of the most common co-reactants for acrylates are thiol (thio-Michael addition). However, thermosetting networks formed by thiol-acrylate reaction generally exhibit flexible structures which limit their applications [11]. A promising way to enhance the mechanical properties is to combine a thiol-acrylate reaction with a thiolepoxy reaction. Thiol-epoxy thermosets already have different applications such as high-performance coatings, adhesives, composites [5] and shape memory materials [12]. Belmonte et al. have successfully developed shape-memory actuators by taking advantage of the sequential dual-curing of off-stoichiometric thiol-epoxy formulations [13]. Combining these materials with liquid-crystalline networks (LCN) forming films in a sandwich-like configuration, they were able to obtain innovative free-standing thermally-triggered "twoway" shape-memory actuators which show an actuator behaviour that can be modulated through the configuration and the stretching level of the LCN [14-15]. The dual-cured material is the substrate, strongly adhered to the LCN layer, that is used as the stress-applying component in the above-mentioned actuator. The key to the successful application of the dual-curing scheme lies in the intermediate material properties: (i) enough storage stability in order to handle the materials and produce the actuator and (ii) the presence 
of unreacted groups in the partially cured material that will ensure good interfacial contact and good adhesion after completion of the second curing process.

Now, the efforts of our group are focused on the development of a similar actuator with a faster and easier activation of the shape memory effect, to reach a greater energy efficiency and make it compatible with an electric control of the temperature. For this purpose, we need to develop custom-tailored thermosets obtained by dual curing procedures with lower transitions temperatures $\left(T_{g}\right)$ and controlled intermediate and final material properties.

A possible way to reduce $T_{\mathrm{g}}$ could be the preparation of thiol-acrylate-epoxy thermosets by a dual-curing process, combining thiol-acrylate Michael addition and thiol-epoxy reaction. The above-mentioned reactions were already used in dual-curing systems. Konuray et al. [16] developed a dual-curing system where the first curing reaction is the thiol-Michael reaction triggered by UV light (a photobase generator was used as catalyst), and the second reaction is a thiol-epoxy reaction between the remaining thiol groups and the epoxides taking place at higher temperature. Jin et al. [17] prepared thiol-epoxy-acrylate hybrid polymer networks combining nucleophilic thiol-acrylate Michael addition and thiol-epoxy reactions in a one-pot simultaneous dual-cure catalyzed by 1,8-diazabicyclo[5.4.0]undec-7-ene (DBU) at $80^{\circ} \mathrm{C}$.

Jian et al. [11] obtained hybrid networks by thiol-epoxy/thiol-acrylate polymerization processes in which both reactions are triggered by irradiation with UV light by use of a photobase generator. Even if reactions proceeded sequentially without a clear separation, they found that thiol-acrylate reactions and acrylate homopolymerization were faster and more efficient than the thiol - epoxy reactions, which reduces the control of the curing process. Gonzalez et al. [18] studied the use of the Aza-Michael addition (amineacrylate) at room-temperature processing of dual-curing formulations and reported much faster kinetics than those commonly observed for amine-epoxy addition [19]. Conversely, the kinetics of Michael reaction are expected to be faster than thiol-epoxy reaction because the nucleophilic addition occurs faster to the acrylate than to the epoxy, and especially because of the slow activation of the thiol-epoxy reaction caused by its strongly autocatalytic character $[10,20]$.

In the present work, we investigate the viability of a thiol-acrylate-epoxy sequential dual-curing system where both reactions are activated using a single thermal catalyst. This system relies on the faster curing kinetics of the thiol-acrylate Michael addition compared to the thiol-epoxy reaction. We expect the thiolacrylate reaction to take place first, delaying the onset of the thiol-epoxy until the complete conversion of the acrylate groups. Therefore, we should obtain a stable thiol-acrylate structure, which can be processed at room temperature. After that, thiol-epoxy reaction could finally take place leading to a fully cured thermoset. The extent of the first reaction is regulated by the acrylate/thiol equivalent ratio $r_{\text {acrylate}}$, which also controls the intermediate material characteristics.

To this purpose, a ternary reactive system containing an epoxy resin (diglycidylether of Bisphenol A, DGEBA), an acrylate monomer (tricyclo[5.2.1.0 $\left.{ }^{2,6}\right]$ decanedimethanol diacrylate, TCDDA, or pentaerythritol 
tetraacrylate, PTTA) and a thiol crosslinker (pentaerythritoltetrakis(3-mercaptopropionate), S4) is studied. Two different tertiary amines (1-methylimidazole, $1 \mathrm{MI}$, and 4-(N,N-dimethylamino)pyridine, DMAP) are used as basic/nucleophilic catalysts and their effects on the curing process are determined. We have focused on the analysis of how both reactions can be combined during a thermally-activated cure and the possibility to obtain a chemically stable material. A fixed $r_{\text {acrylate }}$ was used since our aim is to prove the viability of a thermally activated dual-curing procedure on such systems. The curing process was monitored by means of differential scanning calorimetry (DSC)and Fourier-transform infrared spectroscopy (FTIR). Isoconversional integral analysis were also performed to obtain further information about the curing kinetics of both reactions and to predict the final kinetic behaviour of the dual curing system. Finally, some application tests were made with the materials obtained to understand their potential uses.

\section{EXPERIMENTAL PART}

\subsection{Materials}

Diglycidyl ether of bisphenol A (DGEBA, EPIKOTE ${ }^{\text {TM }}$ Resin 828, with an epoxy equivalent weight of $187 \mathrm{~g} /$ equiv) was supplied by Hexion Specialty Chemicals. Pentaerythritol tetrakis(3-mercaptopropionate) (S4, 122.17 g/eq), tricyclo[5.2.1.0 2,6]decanedimethanol diacrylate (TCDDA, $152.2 \mathrm{~g} / \mathrm{eq}$ )and pentaerythritol tetraacrylate (PTTA, $88.0 \mathrm{~g} / \mathrm{eq}$ ) were provided by Sigma-Aldrich (St. Louis, MO, USA). 1-Methylimidazole (1MI) was purchased from Sigma-Aldrich and 4-(N,N-dimethylamino)pyridine (DMAP) was purchased from Fluka (Switzerland). The epoxy resin was dried under vacuum at $80^{\circ} \mathrm{C}$ for 2 hours prior to use and all the other components were used as received.

The acrylates TCDDA and PTTA were alternatively mixed with S4 and DGEBA with a fixed ratio between acrylate groups and thiol groups $\left(r_{\text {acrylate }}=0.6\right)$. The catalysts $1 \mathrm{MI}$ and DMAP were used in a proportion of 0.25 phr (parts of initiator for hundred parts of mixture) or $0.05 \mathrm{phr}$, respectively. The pure thiol-acrylate $\left(r_{\text {acrylate }}=\right.$ 1) and thiol-epoxy $\left(r_{\text {acrylate }}=0\right)$ formulations were also studied. The samples were prepared by manual stirring of all components in a glass vial and analyzed immediately after. Components were mixed in a specific order: (i) thiol were premixed with the catalysts; (ii) DGEBA was added and the mixture was manually stirred; (iii) finally the acrylate was added and the whole mixture was stirred again. The entire preparation was carried out with the vial immersed in a pot with crushed ice to prevent premature activation of the first curing reaction, thus allowing a more precise characterization of the curing kinetics. The composition and notation of the pure formulations under investigation is detailed in Table 1, while composition and notation of dual formulations with $r_{\text {acrylate }}=0.6$ are presented in Table 2 . 
Table 1. Composition of the pure formulations of study.

\begin{tabular}{|c|c|c|c|c|}
\hline & Formulation & Thiol (wt \%) & DGEBA (wt \%) & Acrylate (wt\%) \\
\hline Thiol-Epoxy & $\begin{array}{l}\text { S4DGEBA.1MI } \\
\text { S4DGEBA.DMAP }\end{array}$ & 39.5 & 60.5 & 0.0 \\
\hline \multirow{2}{*}{ Thiol-Acrylate } & $\begin{array}{l}\text { S4TCDDA.1MI } \\
\text { S4TCDDA.DMAP }\end{array}$ & 44.5 & 0.0 & 55.5 \\
\hline & $\begin{array}{c}\text { S4PTTA.1MI } \\
\text { S4PTTA.DMAP }\end{array}$ & 58.1 & 0.0 & 41.9 \\
\hline
\end{tabular}

Table 2. Composition of the dual formulation with $\mathrm{r}_{\text {acrylate }}=0.6$.

\begin{tabular}{|c|c|c|c|c|}
\hline & Formulation & Thiol (wt \%) & DGEBA (wt \%) & Acrylate (wt\%) \\
\hline \multirow{2}{*}{$\begin{array}{l}\text { Dual } \\
\text { Formulations }\end{array}$} & $\begin{array}{l}\text { S4TCDDA06.1MI } \\
\text { S4TCDDA06.DMAP }\end{array}$ & 42.4 & 25.9 & 31.7 \\
\hline & $\begin{array}{l}\text { S4PTTA06.1MI } \\
\text { S4PTTA06.DMAP }\end{array}$ & 49.0 & 29.9 & 21.1 \\
\hline
\end{tabular}

\subsection{Characterization techniques}

A differential scanning calorimeter (DSC) Mettler DSC-821e, calibrated using an In standard (heat flow calibration) and an In-Pb-Zn standard (T calibration), was used to study the cure. Samples of approximately $5 \mathrm{mg}$ were tested in aluminium pans with a pierced lid in $\mathrm{N}_{2}$ atmosphere with a gas flow of $50 \mathrm{~mL} / \mathrm{min}$. Dynamic studies between 0 and $200^{\circ} \mathrm{C}$ with a heating rate of $10^{\circ} \mathrm{C} / \mathrm{min}$ were performed to characterize the curing process and measure final $\mathrm{T}_{\mathrm{g}} \mathrm{s}$. Isothermal curings were also performed at $30,60,80$ and $100^{\circ} \mathrm{C}$. The calorimetric degree of conversion was determined as $x_{D S C}=\Delta h / \Delta h_{t o t}$, where $\Delta h$ is the reaction heatreleased up to a temperature $\mathrm{T}$ or time $\mathrm{t}$ and $\Delta h_{t o t}$, is the totalreaction heat evolved in a dynamic run. The calorimetric rate was determined as $d x_{D S C} / d t=(d h / d t) / \Delta h_{t o t}$, where $d h / d t$ is the heat flow. Intermediate $\mathrm{T}_{\mathrm{g}}$ were measured with a two-step DSC procedure: (i) isothermal curing at $30^{\circ} \mathrm{C}$ until the first reaction comes to the end; (ii) dynamic heating from -20 to $100^{\circ} \mathrm{C}$.

A FTIR spectrometer Bruker Vertex 70 with an attenuated total reflection accessory with thermal control and a diamond crystal (Golden Gate Heated Single Reflection Diamond ATR, Specac-Teknokroma) and equipped with a mid-band liquid nitrogen-cooled mercury-cadmium-telluride (MCT) detector was used to monitor thiol, acrylate and epoxy conversions during isothermal curing at temperatures ranging from 30 to $80^{\circ} \mathrm{C}$. Realtime spectra were collected in absorbance mode with a resolution of $4 \mathrm{~cm}^{-1}$ in the wavelength range from 
4000 to $600 \mathrm{~cm}^{-1}$ averaging 20 scans for each spectrum. The characteristic absorbance peak of the acrylate at $810 \mathrm{~cm}^{-1}$ was used to monitor the conversion of the acrylate groups during the thiol-acrylate Michael reaction. The disappearance of the absorbance peak at $915 \mathrm{~cm}^{-1}$ (epoxy bending) [21] and at $860 \mathrm{~cm}^{-1}$ were used to monitor the reaction of epoxy groups. The absorbance peak at $3500 \mathrm{~cm}^{-1}$, related to the formation of $\mathrm{OH}$ during the epoxy-thiol reaction, was also used to monitor the conversion of the epoxy groups only from a qualitative point of view. Absorbances of each scanned sample were normalized with that of the ester group $\left(1720 \mathrm{~cm}^{-1}\right)$. Acrylate conversion of functional groups is calculated by Eq. (1),

$$
x_{\text {acrylate }}=1-\frac{A^{\prime}{ }_{810}}{A^{\prime}{ }_{810,0}}
$$

Where $A_{810}^{\prime}$ and $A_{810,0}^{\prime}$ are the normalized absorbances of the acrylate peak at $810 \mathrm{~cm}^{-1}$ at a given reaction time and at the beginning of the curing process, respectively.

Since the direct evaluation of epoxy group conversion using the epoxy peak at $915 \mathrm{~cm}^{-1}$ could be difficult [22], we have calculated the conversion using the peak at $860 \mathrm{~cm}^{-1}$ using Eq. (2).

$$
x_{\text {epoxy }}=1-\frac{A^{\prime}{ }_{860}}{A^{\prime} 860,0}
$$

Where $A_{860}^{\prime}$ and $A_{860,0}^{\prime}$ are the normalized absorbances of the epoxy peak at $860 \mathrm{~cm}^{-1}$ at a given reaction time and at the beginning of the curing process, respectively.

\section{THEORETICAL PART}

\subsection{Reaction mechanisms}

Thiol-acrylate Michael addition reaction can be catalysed by bases or nucleophilic initiators [23]. For a weakly basic but nevertheless nucleophilic amine such as $1 \mathrm{MI}$, the thiol-acrylate reaction would take place following the nucleophilic mechanism [5,23], represented in Scheme 1, involving a number of reaction steps. First, the nucleophilic Michael addition of the $1 \mathrm{MI}$ to the acrylate (Scheme 1.a) results in an enolate anion stabilized by resonance and by the positive charge of the imidazolium cation. Moreover, due to its basic character, the enolate is capable to abstract a hydrogen from the thiol producing the thiolate and a $\beta$-imidazolium ester (Scheme 1.b). The strongly nucleophilic thiolate anion is able to undergo direct conjugate addition to the acrylic $\mathrm{C}=\mathrm{C}$ bond yielding an enolate intermediate that deprotonates additional thiol generating the reaction 
product and regenerating the thiolate anion, which continues propagating the reaction (Scheme 1.c). Thanks to the enolate stabilization in the initiation step, the thiolate formation in (a) could have a lower reaction rate than the recuperation of the thiolate in (Scheme 1.c). Lastly, as shown in (Scheme 1.d), there is a possibility of the $1 \mathrm{MI}$ regeneration through the nucleophilic displacement, but we assume that this is a minor and slow process.

\section{a. Activation}<smiles></smiles><smiles>Cn1cc[n+](CC=C([O])[O-])c1</smiles><smiles>[2H][O+]OC([O-])=CC[n+]1ccn(C)c1</smiles><smiles>C=C=C</smiles>

\section{b. Nucleophilic thiolate-acrylate attack}<smiles>[R]OC(=O)C1CCCC1=CCC[S+][R]</smiles>

\section{c. Enolate-thiol proton exchange}<smiles>[R][SH2+][S-]</smiles>

\section{d. Termination / regeneration}

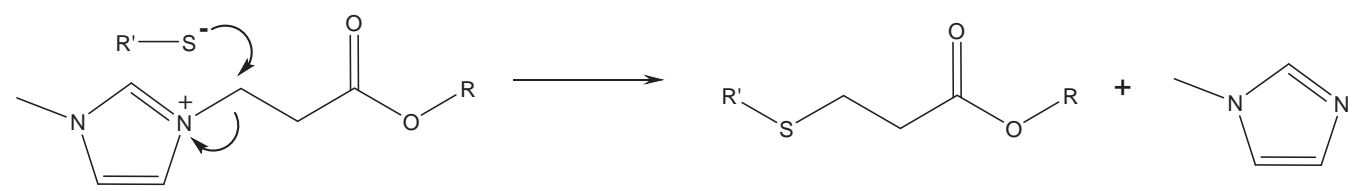

Scheme 1. Proposed curing mechanism of thiol-acrylate Michael reaction catalyzed by tertiary amines

Nucleophile-mediated thiol-epoxy reaction follows a similar reaction mechanism, as shown for weakly basic but nucleophilic tertiary amines such as 1MI and BDMA [24]. Scheme 2 shows the proposed mechanism using $1 \mathrm{Ml}$ as the initiator. The activation step (Scheme 2.a) starts with the nucleophilic attack of the tertiary amine on the epoxy ring. Then, the proton exchange between the alkoxide, produced in the previous step, and a thiol group yield a thiolate together with a hydroxyammonium compound. The thiolate anion follows the reaction by means of a nucleophilic addition to the epoxy ring, which leaves an alkoxide intermediate 
(Scheme 2.b). The thiolate regeneration in (Scheme 2.c) by proton exchange of the formed alkoxide with another thiol, leads to the thio-ether condensation product with a hydroxyl group ( $\beta$-hydroxythio-ether). The initiator could be regenerated by a nucleophylic reaction (Scheme 2.d) which also leads to the reaction product, with a non-negligible contribution to the overall process [20]. Both activation and nucleophilic attack of the thiolate to the epoxide are catalyzed by hydroxyl groups, therefore the hydroxyl groups produced in the thiol-epoxy reaction should favour the nucleophilic attacks to the epoxy ring [25,26], hence the reported strong autocatalytic effect $[10,20]$. Overall, the reaction mechanism is not different from that of the basecatalyzed thiol-epoxy reaction [10, 27]. The main differences lie in the activation step (Scheme 2.a) and the existence of a regeneration (Scheme 2.d), which may have some consequence in terms of the reaction kinetics $[10,20]$.

\section{a. Activation}
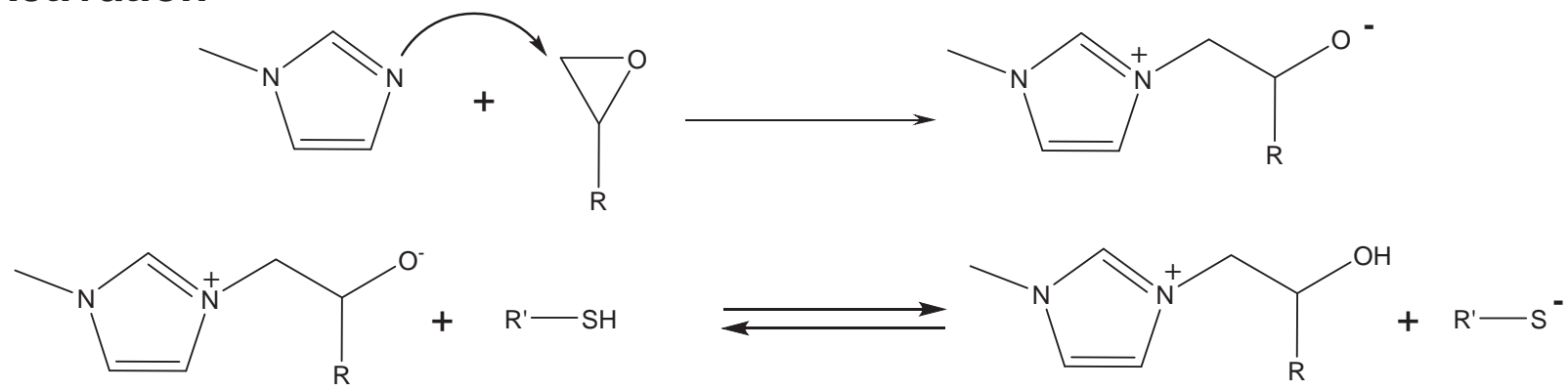

\section{b. Nucleophilic thiolate-epoxy attack}
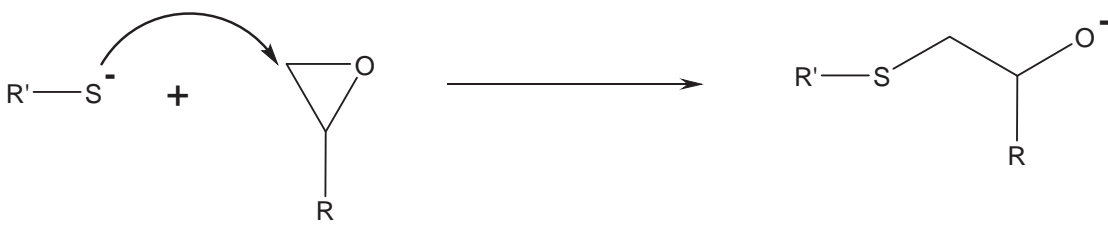

\section{c. Alkoxide-thiol proton exchange}<smiles>[R]SCC([O-])P</smiles>

\section{d. Regeneration of the catalyst}

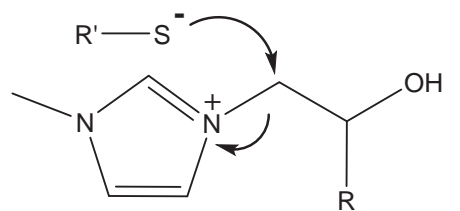<smiles>Cn1ccnc1</smiles>

Scheme 2. Proposed curing mechanism of thiol - epoxy reaction catalyzed by tertiary amines. 


\subsection{Network formation}

The crosslinking process is illustrated in Scheme 3. During the first curing stage the reaction between thiol and acrylate groups takes place forming a first network made up of thiol (green) and acrylate(red) in which an excess of thiol groups is left unreacted. Consequently, the second curing stage, consisting in the reaction between unreacted thiol groups and epoxy groups (blue), completes the network build up leading to a fully crosslinked structure without any unreacted ends. Since the thiol-acrylate and thiol-epoxy networks are quite similar, the resulting structure is expected to be homogeneous with a narrow glass transition.<smiles>O=C(CCS)OCC(COC(=O)CCS)(COC(=O)CCS)OC(=O)CCS</smiles><smiles>C=CC(=O)OCC1CC2CCC1C2COC(=O)OCC1CC1</smiles>
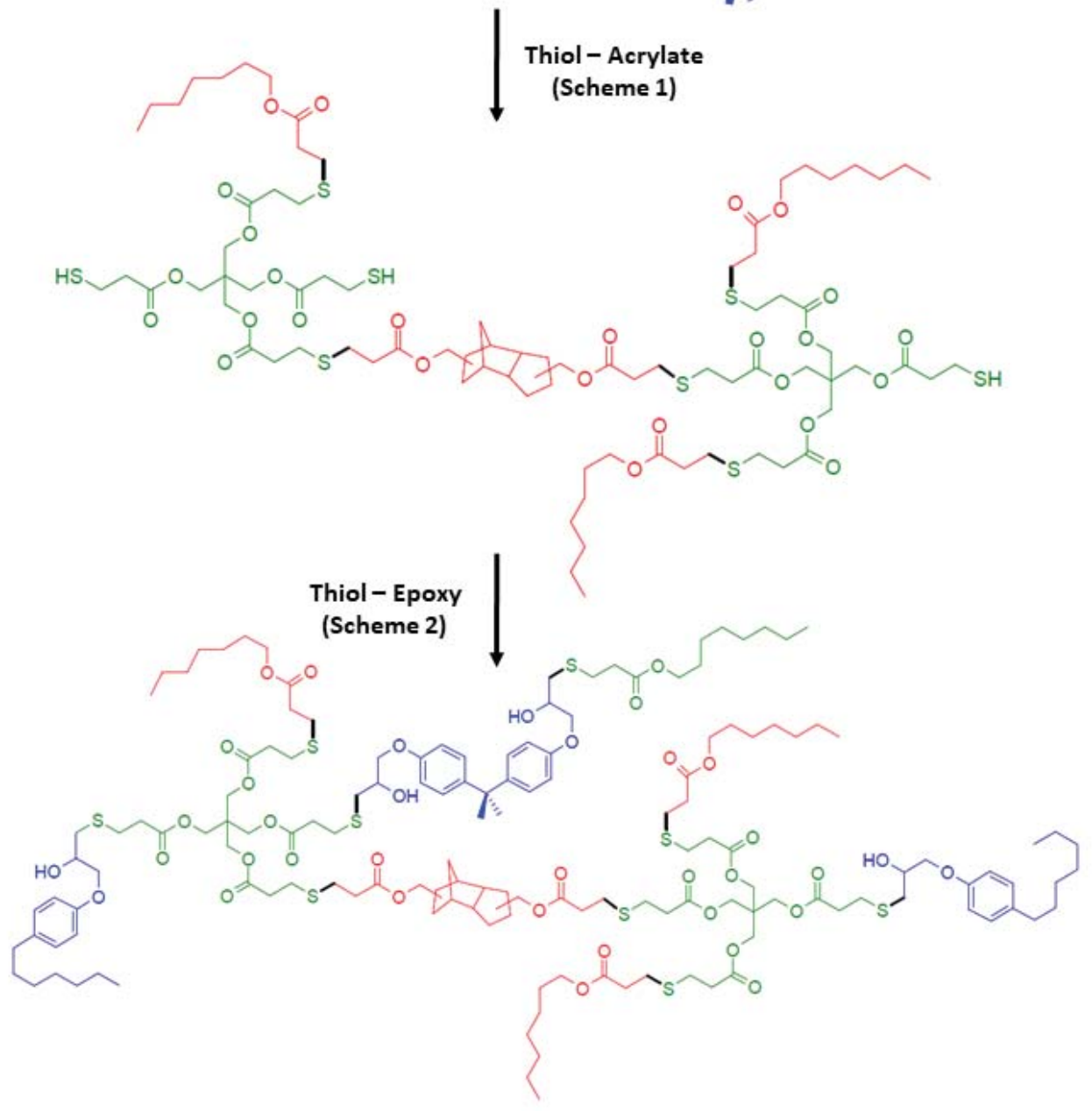

Scheme 3. Expected network structure formed by thiol-acrylate-epoxy from DGEBA, TCDDA and S4 formulations 
The prediction of the crosslinking degree of the intermediate state represents a key factor in dual curing formulation design. In this case it is of interest, therefore, to analyze whether gelation occurs during the thiolacrylate reaction, in the first stage of the curing process. Although Scheme 1 indicates the presence of different reaction steps (i.e. activation, propagation,...) , the cyclic propagation of the thiol-Michael reaction through the nucleophilic attack of the thiolate to the acrylate, followed by regeneration of the thiolate anion, should take place in a random and step-wise manner as in other reactions such as epoxy-acid [28] or epoxyphenol [29] processes. Neglecting the effect of the initiator-acrylate adducts, the molecular/network structure build-up process can therefore be approximately analyzed assuming ideal step-wise behaviour [1] , and therefore the conversion of acrylate groups at the gel point can be calculated using the well-known Flory-Stockmayer expression:

$$
x_{\text {acrylate, gel }}=\left[r_{\text {acrylate }} \cdot\left(f_{\text {acrylate }}-1\right) \cdot\left(f_{\text {thiol }}-1\right)\right]^{-1 / 2}
$$

Where $f_{\text {acrylate }}$ and $f_{\text {thiol }}$ are the average functionality of epoxy and thiol monomers and $r_{\text {acrylate }}$ is defined as the ratio between acrylate and thiol equivalents. This only produces a valid gel point conversion for values of $r_{\text {acrylate }}$ higher than $r_{c}$, where $r_{c}$ is the critical gelation ratio (4).

$$
r_{c}=\frac{1}{\left(f_{\text {acrylate }}-1\right) \cdot\left(f_{\text {thiol }}-1\right)}
$$

Moreover, using the Fox equation [1], we can estimate the glass transition temperatures of the intermediate material $\left(T_{g, 1}\right)$ and the final thermoset $\left(T_{g, 2}\right)$ for any $r_{\text {acrylate }}$. To perform this calculation, $T_{g}$ of the uncured epoxy-thiol system $\left(T_{g,(e-t)}^{0}\right)$ and $T_{\mathrm{g}}$ of the cured epoxy-thiol $\left(T_{g,(e-t)}^{\infty}\right)$ and acrylate-thiol systems $\left(T_{g,(a-t)}^{\infty}\right)$ are required.

$$
\begin{aligned}
& \frac{1}{T_{g, 1}}=\frac{w_{a-t}}{T_{g(a-t)}(a)}+\frac{1-w_{a-t}}{T_{g,(e-t)}(e-1)} \\
& \frac{1}{T_{g, 2}}=\frac{w_{a-t}}{T_{g(a-t)}^{\infty}}+\frac{1-w_{a-t}}{T_{g,(e-t)}^{\infty}}
\end{aligned}
$$

where $w_{a-t}$ is the weight fraction of the acrylate plus the part of thiol which participate to the first curing reaction. 


\subsection{Isoconversional kinetics analysis}

The curing kinetics have been analyzed using isoconversional method [30]. This methodology is based on the assumption that the rate $d x / d t$ of a given process can be expressed as separate functions of temperature $T$ and degree of conversion $x$

$$
\frac{d x}{d t}=k(T) f(x)
$$

$k(T)$ is the rate constant, which is usually expressed with an Arrhenius-like temperature dependence, $k(T)$ $=k_{0} \cdot \exp (-E / R T)$, where $k_{0}$ is the pre-exponential factor and $E$ is the activation energy. $f(x)$ is the kinetic model function representing the underlying reaction mechanism and depends on the extent of conversion $x . k_{0}, E$ and $f(x)$ represent the so-called kinetic triplet, which are necessary to completely describe a process. Under the isoconversional assumptions, the reaction mechanism does not depend on the temperature programme and one can write

$$
\frac{d \ln (d x / d t)}{d T^{-1}}=\frac{d \ln (f(x))}{d T^{-1}}+\frac{d \ln (k(T))}{d T^{-1}} \equiv-\frac{E_{x}}{R}
$$

Where $E_{x}$ is the apparent activation energy. Linearization of the rate expression leads to the differential isoconversional method of Friedman [30-32], but in the present work we propose to use an integral isoconversional method. The rate expression can be integrated under isothermal conditions [30] as follows:

$$
g(x)=\int_{0}^{x} \frac{d x}{f(x)}=\int_{0}^{t} k_{0} \exp \left(\frac{-E}{R T}\right) d t=k_{0} \exp \left(\frac{-E}{R T}\right) t
$$

Where $g(x)$ is the integral form of the kinetic model. Now, taking the natural logarithm of both sides of the equation, we obtain:

$$
\ln t_{x, i}=\ln \left[\frac{g(x)}{k_{0, x}}\right]+\frac{E_{x}}{R T_{i}}
$$

Plotting $\ln t_{x, i}$ versus $1 / R T_{i}$ at fixed conversion $x$ and at different curing temperature $T_{i}$ s we obtain a line with $E_{x}$ as slope and $\ln \left[g(x) / k_{0, x}\right]$ as the intercept at the origin. 


\section{RESULT AND DISCUSSION}

\subsection{Studies on pure formulations}

First of all, we investigated the curing kinetics of pure thiol-epoxy and pure thiol-acrylate formulations by means of DSC isothermal analysis and isoconversional analysis. The results obtained will allow us to better understand the curing behaviour of the complete thiol-acrylate-epoxy formulations. A heat released of about $60 \mathrm{KJ} /$ eq by thiol-acrylate reaction catalysed by $1 \mathrm{MI}(0.25 \mathrm{phr})$, measured by means of DSC dynamic scan at $10^{\circ} \mathrm{C} / \mathrm{min}$, was taken as a reference given that no similar data were found in the literature.

Figure 1 compares the isothermal curing at $30^{\circ} \mathrm{C}$ performed on pure acrylate - $\mathrm{S} 4$ formulations with different catalyst. It is shown that in the case of PTTA, the use of 0.05 phr of DMAP leads to a faster activation of the curing reaction and shorter curing time. No significant effects of the catalyst on reaction time was detected using TCDDA. In this case, the use of DMAP seems only to overcome the reaction complexities evidenced by the shape of the curing peeks obtained using $1 \mathrm{MI}$ as catalyst. However, the reaction between TCDDA and S4 results in a longer reaction time, with both catalysts, possibly due to the presence of some poisoning (acidic) impurities in TCDDA, or else some steric hindrance caused by the rigid tricyclic structure.

Figure 2.a compares the isothermal curing at $30^{\circ} \mathrm{C}$ of pure DGEBA-S4 and TCDDA-S4 formulations. It is clearly observed that, because of the slower activation and kinetics of the thiol-epoxy reaction, the two reactions take place in different ranges of time leaving an overlapping region which almost disappears using DMAP as catalyst. Using PTTA as acrylate (Figure 2.b), the overlapping decreases because of the faster thiol-acrylate reaction. PTTA and DMAP seems to be the best combination in terms of separation but it leads to difficulties in controlling the first reaction. Therefore, a good separation between thiol-acrylate and thiol-epoxy systems would be obtained using TCDDA as acrylate and DMAP as initiator, or else using PTTA as acrylate. 


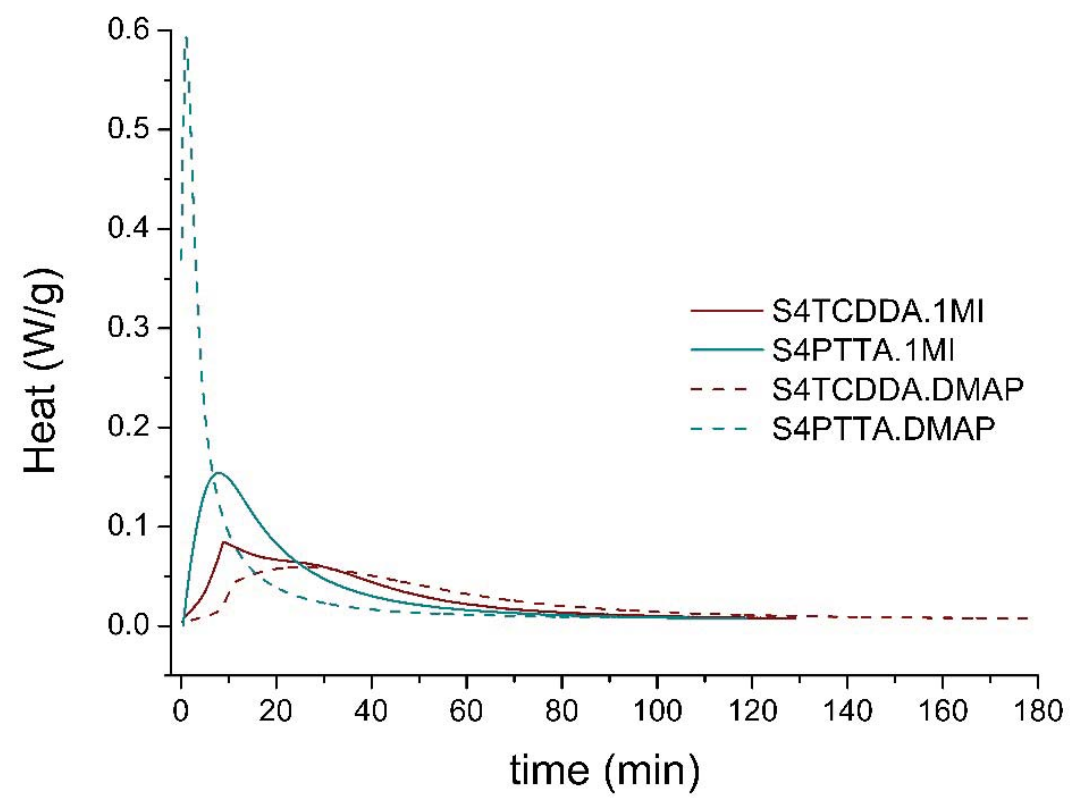

Figure 1. Effects of the catalyst and acrylate type on isothermal DSC analysis at $30^{\circ} \mathrm{C}$ of thiol-acrylate formulations
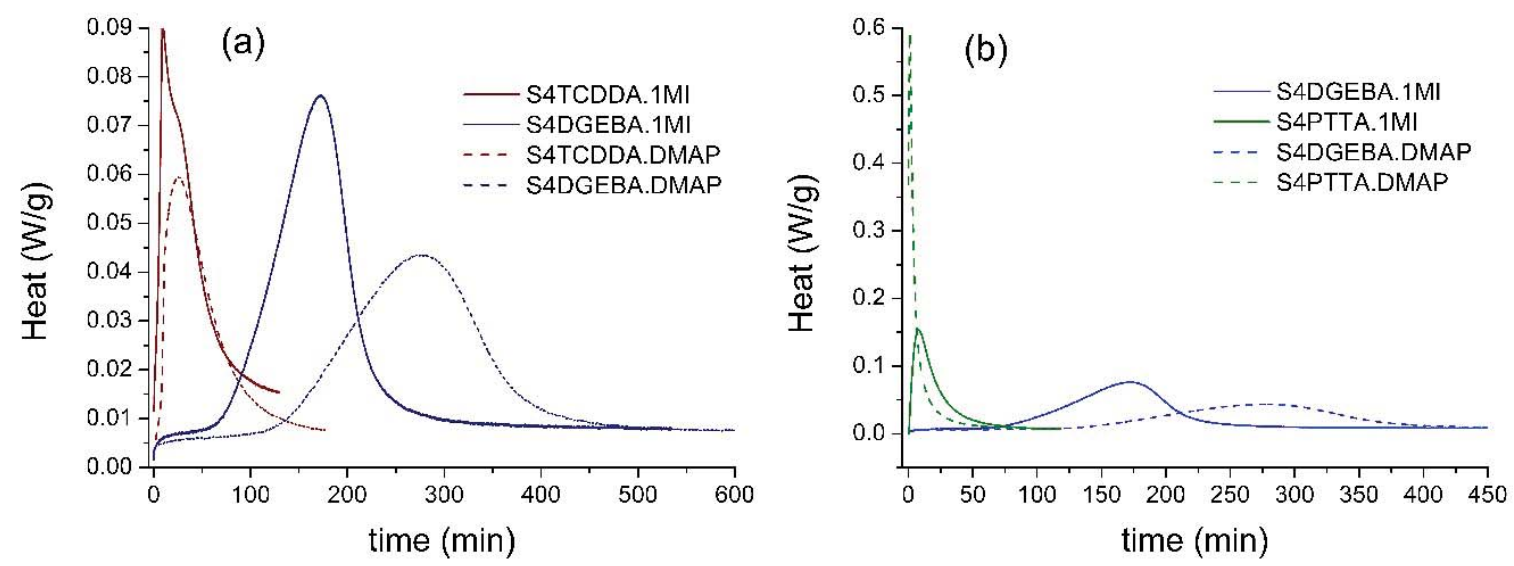

Figure 2. Comparison between DSC isothermal analysis of thiol-epoxy and thiol-acrylate (TCDDA in (a) and PTTA in (b)) formulations obtained using $1 \mathrm{MI}$ and DMAP as initiators

Table 3 collects some characteristic parameters of the curing process along with glass transition temperatures and heat capacity variation associated with the transition. The heat released during isothermal curing of thiol-acrylate was found to be around 40-50 kJ/eq, but our measurements are affected by experimental error resulting from the fast initial reaction rate and the slow kinetics at the end of the curing process. The reaction heat values for the epoxy-thiol formulations were measured during isothermal curing at $60^{\circ} \mathrm{C}$ instead of the $30^{\circ} \mathrm{C}$ (too long reaction time and vitrification led to unreliable results at $30^{\circ} \mathrm{C}$ ), producing values around $130 \mathrm{~kJ} / \mathrm{eq}$, similar to those previously reported [24]. In this case, the slow activation 
of the thiol-epoxy process and the autocatalytic character of the reaction, leading to a faster reaction end, ensured a more reliable detection of the reaction heat. Glass transition temperatures of the obtained thermosets were also measured (Table 3).

Table 3. Calorimetric data: isothermal reaction heat measured after $60^{\circ} \mathrm{C}$ isothermal for S4DGEBA.1MI and S4DGEBA.DMAP and after $30^{\circ} \mathrm{C}$ isothermal for S4TCDDA.1MI, S4TCDDA.DMAP, S4PTTA.1MI, S4PTTA.DMAP.

\begin{tabular}{|c|c|c|c|c|c|c|}
\hline Formulation & $\Delta \mathrm{H}(\mathrm{J} / \mathrm{g})$ & $\Delta \mathrm{H}(\mathrm{kJ} / \mathrm{eq})$ & $\mathrm{T}_{\mathrm{g}, 0}\left({ }^{\circ} \mathrm{C}\right)$ & $\Delta \mathrm{cp}_{0}(\mathrm{~J} / \mathrm{gK})$ & $\mathrm{T}_{\mathrm{g}, \infty}\left({ }^{\circ} \mathrm{C}\right)$ & $\Delta c p_{\infty}(\mathrm{J} / \mathrm{gK})$ \\
\hline S4DGEBA.1MI & 408 & 126 & \multirow{2}{*}{-34} & \multirow{2}{*}{0.393} & \multirow{2}{*}{50} & \multirow{2}{*}{0.25} \\
\hline S4DGEBA.DMAP & 439 & 135 & & & & \\
\hline S4TCDDA.1MI & 166 & 45 & & & \multirow{2}{*}{13} & \multirow{2}{*}{0.34} \\
\hline S4TCDDA.DMAP & 169 & 46 & & & & \\
\hline S4PTTA.1MI & 200 & 42 & & & \multirow{2}{*}{15} & \multirow{2}{*}{0.35} \\
\hline S4PTTA.DMAP & 199 & 41 & & & & \\
\hline
\end{tabular}

S4DGEBA.DMAP shows a $\mathrm{T}_{\mathrm{g}, \infty}$ of $50^{\circ} \mathrm{C}$ in accordance with results obtained in other works [13]. Regarding thiol-acrylate formulation, S4TCDDA.DMAP and S4PTTA.DMAP have a $\mathrm{T}_{\mathrm{g}, \infty}$ of, respectively, $13^{\circ} \mathrm{C}$ and $15^{\circ} \mathrm{C}$. Although PTTA has a higher functionality than TCDDA, final thermosets do not show an appreciable difference in terms of $\mathrm{T}_{\mathrm{g}, \infty}$. This could be ascribed to the highly rigid structure of the linear and lesser-functional TCDDA monomer.

Kinetic analysis of pure thiol-epoxy and thiol-acrylate formulations were performed with the purpose of obtaining the apparent activation energy of the thiol-epoxy $\left(E_{t h-e p o}\right)$ and thiol-acrylate $\left(E_{t h-a c r}\right)$ reactions, making use of the isoconversional integral method described in the theoretical section. For the thiol-epoxy reaction, isothermal curing of DGEBA.1MI formulation was carried out in the DSC at 60,80 and $100^{\circ} \mathrm{C}$. For the thiol-acrylate reaction, the curing of S4TCDDA.1MI was monitored at 40,60 and $80^{\circ} \mathrm{C}$ by FTIR. The choice of different instruments to obtain kinetic data was caused by the difficulty of determining accurately the thiol-acrylate reaction kinetics by DSC (because of their very high reaction rate at higher temperatures, leading to a significant loss of data at the beginning of the process), and the precise determination of the epoxy group conversion in thiol-epoxy reactions using FTIR (because of overlapping signals)[5]. However, this change in methodology should produce equally good results if the curing temperature can be controlled in a suitable way.

In Figure 3 the conversion-time curves at different temperatures for both systems are represented. Figure 3.a shows that the thiol-acrylate reaction is very fast, with almost immediate activation after mixing, while Figure 3.b shows that the thiol-epoxy reaction is slower, with a clear autocatalytic character with a long induction period before activation. This was expected from the discussion of the reaction mechanisms and the preliminary calorimetric analysis. Although the reaction rates are comparable at higher temperatures, 
the thiol-epoxy reaction is clearly faster at lower temperatures (i.e. below $80-60^{\circ} \mathrm{C}$ ). Noticeably, the thiolacrylate reaction has a very weak temperature dependence in contrast with the thiol-epoxy reaction. This is confirmed by the results of the isoconversional analysis of both curing processes. In spite of the uncertainty in the analysis of kinetic data and the determination of the kinetic parameters, especially for the thiolacrylate reaction at higher temperatures, the apparent activation energy of the thiol-acrylate reaction ( $\left.E_{t h-a c r}\right)$ was found to be around $20 \mathrm{~kJ} / \mathrm{mol}$, while that of the thiol-epoxy reaction $\left(E_{t h-e p o}\right)$ is about 70 $\mathrm{kJ} / \mathrm{mol}$. The values are rather constant, suggesting that the underlying curing mechanisms do not change

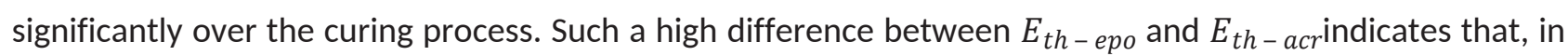
presence of both acrylate and epoxy groups, the reaction between thiol and acrylate is more favourable than thiol- epoxy, which would only take place when acrylate groups are close to the total conversion. In addition, the thiol-epoxy reaction would slow down more significantly than the thiol-acrylate reaction at lower temperatures, i.e. room temperature, in agreement with the preliminary calorimetric results reported in Figure 2.
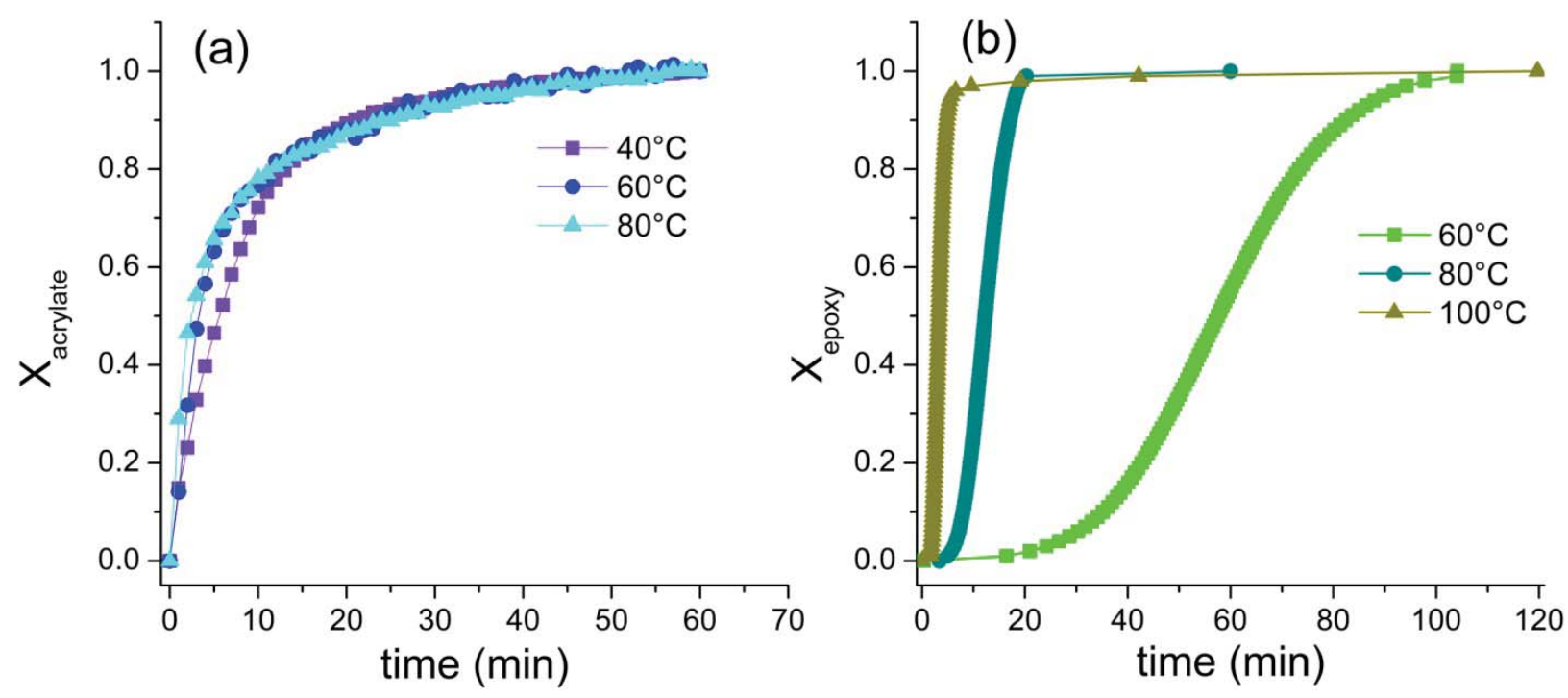

Figure 3. (a) FTIR acrylate conversion - time plots of S4TCDDA.DMAP formulations cured at $40,60,80^{\circ} \mathrm{C}$; (b) DSC conversion curves of S4DGEBA.DMAP formulations at $60,80,100^{\circ} \mathrm{C}$.

In consequence, a dual-curing system combining both reactions would show a better separation between the reaction processes and, therefore, a greater selectivity if the first stage were carried out at temperatures as low as room temperature. In the first stage, only the thiol-acrylate reaction would take place, with little overlap between the thiol-acrylate and the thiol-epoxy reaction. If the system were kept at the same temperature, the thiol-epoxy reaction would eventually activate and reach completion, but at a sluggish rate. 
Therefore, the second stage, where only the thiol-epoxy reaction would occur, should take place at a higher temperature to shorten the curing cycle. Following this procedure, an almost sequential and controllable dual-curing system could be achieved. Lastly, we were able to plot the $T_{\mathrm{g}} \mathrm{s}$ of intermediate and final materials as a function of $r_{\text {acrylate }}$ by means of a theoretical evaluation based on Fox equation (Figure 4). The critical ratio $r_{\text {critical }}$ was calculated thanks to the Flory-Stockmayer theory, as explained in the theoretical part. As shown in Figure 4, a range of intermediate and final materials would be obtained using TCDDA and PTTA as acrylates. There is very little influence of the type of acrylate on the intermediate and final $T_{\mathrm{g}} \mathrm{s}$, but the material structure, especially in the intermediate state, would be entirely different. This is caused by the higher functionality of PTTA $(f=4)$, leading to lower critical ratios than TCDDA $(f=2)$ (see Figure 4). Depending on

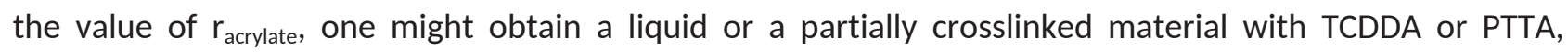
respectively. The use of PTTA enables the preparation of partially crosslinked intermediate materials for a wider range of formulations. Taking into account this evaluation, dual-curing formulations with $r_{\text {acrylate }}=0.6$ were prepared and characterized. We choose this particular ratio in order to work with an unbalanced proportion between acrylate and epoxy which ensures gelled intermediate materials for both acrylates, and in order to have a more balanced contribution of both thiol-acrylate and thiol-epoxy reactions in terms of reaction heat.

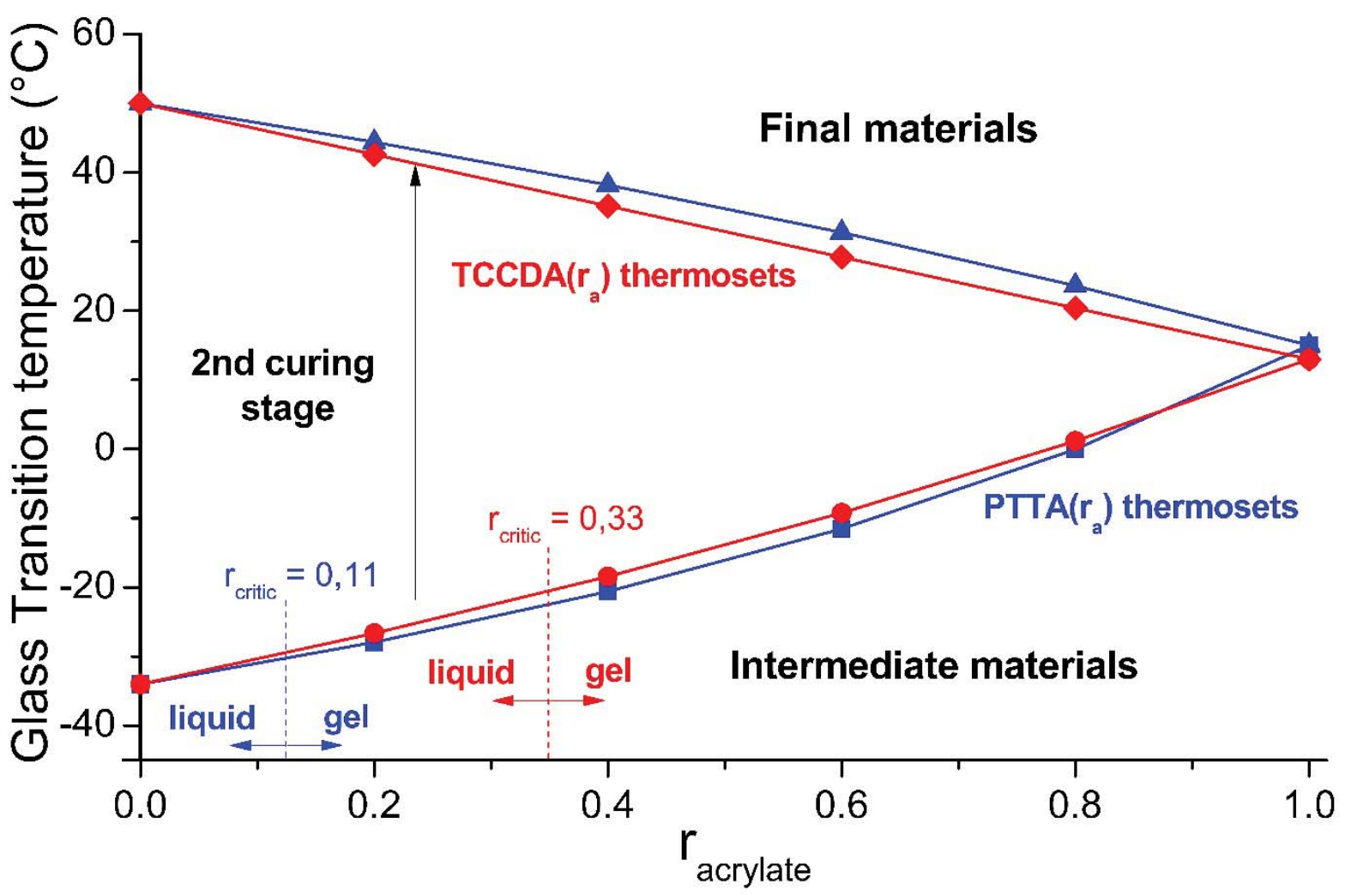

Figure 4. Theoretical evaluation of glass transition temperatures along with $r_{\text {acrylate }}$ for TCDDA-DGEBA and PTTA-DGEBA dual curing formulations. 


\subsection{Viability of dual-curing of Thiol-Acrylate-Epoxy formulations}

The viability of the dual-curing formulations has been analyzed using DSC and FTIR. Calorimetric analyses have been carried out using $0.05 \mathrm{phr}$ of DMAP on account of the better results, in terms of reactions separation, evidenced in the previous section. However, FTIR analysis has been performed on dual formulations with both $1 \mathrm{MI}$ and DMAP.

Figure 5 and Figure 6 show the isothermal curing at $30^{\circ} \mathrm{C}$ of dual-curing formulations and the results of their calorimetric analysis are summarized in Table 4. Figure 5 shows the curing process of S4TCDDA06.DMAP at $30^{\circ} \mathrm{C}$ and compares it with the curing of S4DGEBA.DMAP and S4TCDDA.DMAP at the same temperature. It can be noticed that the dual S4TCDDA06.DMAP shows two well-defined reaction regions which should be associated with the thiol-acrylate and the thiol-epoxy reactions, respectively. The first reaction peak takes place within the same time range as the neat S4TCDDA.DMAP system but, in contrast, the second reaction peak is significantly delayed and slowed down (peak onset at about 300 minutes) in reference to the S4DGEBA.DMAP system (peak onset at about 100 minutes). An interval of separation is clearly visible between the two stages proving that the two reactions are sequential. During this interval, even if the second reaction is already beginning it proceeds with a very low rate allowing us to obtain an intermediate material that could be considered as stable at room temperature. In addition, the reaction heat of $58 \mathrm{~kJ} / \mathrm{eq}$, released during the first stage (see Table 4), is quite close to the reference heat released by neat thiol-acrylate systems, confirming that the first process comes to the end. The significant delay and slowing down of the second reaction is mainly caused by the dilution of the thiol-epoxy formulation in the dual system. The dilution of epoxy groups would obviously slow down the reaction, but it is the dilution of the concentration of catalytic hydroxyl groups coming from the oligomeric DGEBA structure and formed in the thiol-epoxy reaction that produce a further delay in the reaction onset and decrease in the reaction rate. Note that the thiol-acrylate reaction does not produce any species that can contribute to the catalysis of the thiol-epoxy reaction. This observation is in close agreement with our previous analysis of the reaction mechanism of thiol-epoxy systems [20]. In addition, termination and trapping reaction in the thiol acrylate mechanism together with the partial consumption of the catalyst after the completion of the first reaction, can lead to the reduction of available catalyst and active species for the second reaction. 


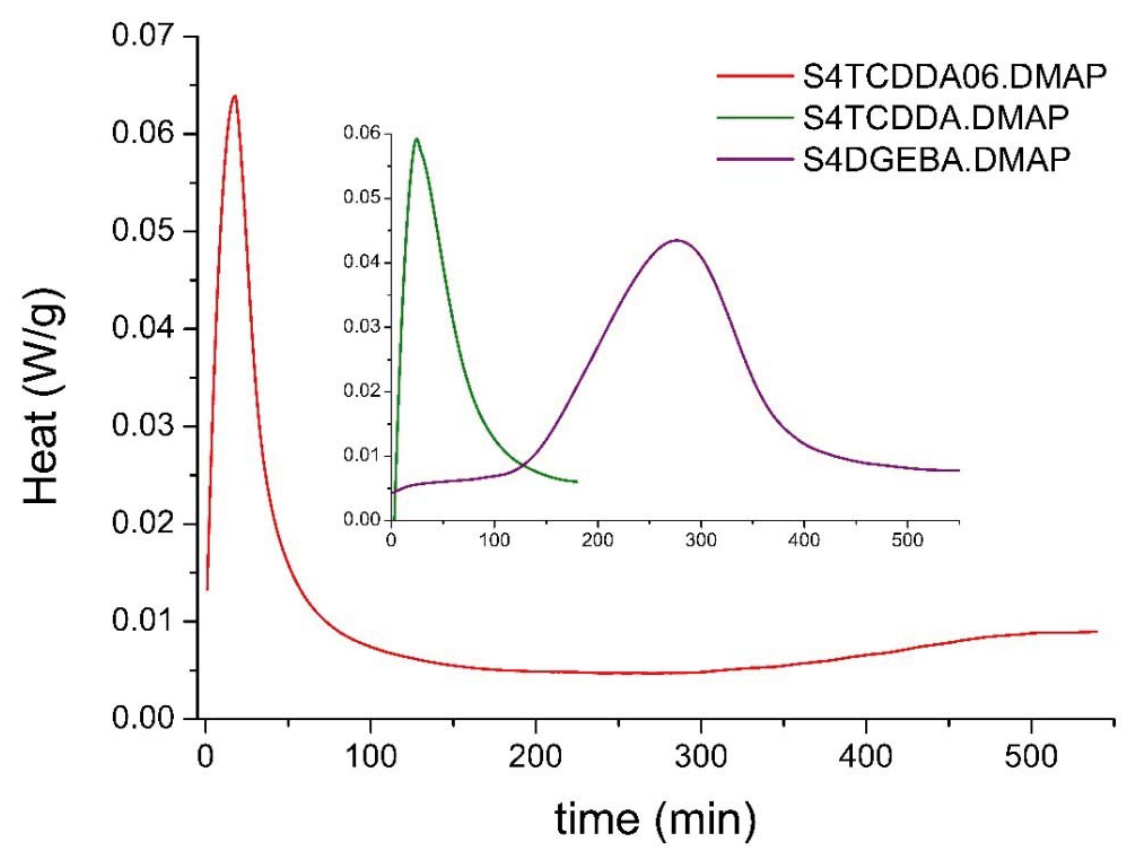

Figure 5. DSC thermograms of isothermal curing at $30^{\circ} \mathrm{C}$ of S4TCDDA06; DSC thermograms of isothermal curing at $30^{\circ} \mathrm{C}$ of S4DGEBA.DMAP and S4TCDDA.DMAP(inset).

The curing process at $30^{\circ} \mathrm{C}$ for the S4TCDDA06.DMAP and S4PTTA06.DMAP formulations are compared in Figure 6. The most visible difference is that PTTA gives a very fast reaction that makes the $1^{\text {st }}$ stage quite difficult to control. The entire curing process is shifted to shorter times and the separation between the curing stages is more or less the same as that obtained with TCDDA. In both cases, the second curing stage is difficult to observe because of the very low reaction rate at which occurs, but the inset in Figure 6 clearly shows the occurrence of the thiol-epoxy reaction. In any case, the results in Figure $\mathbf{5}$ and Figure $\mathbf{6}$ evidence that curing nearby room temperature delays the starting of the thiol-epoxy and promote the separation between the curing stages. 


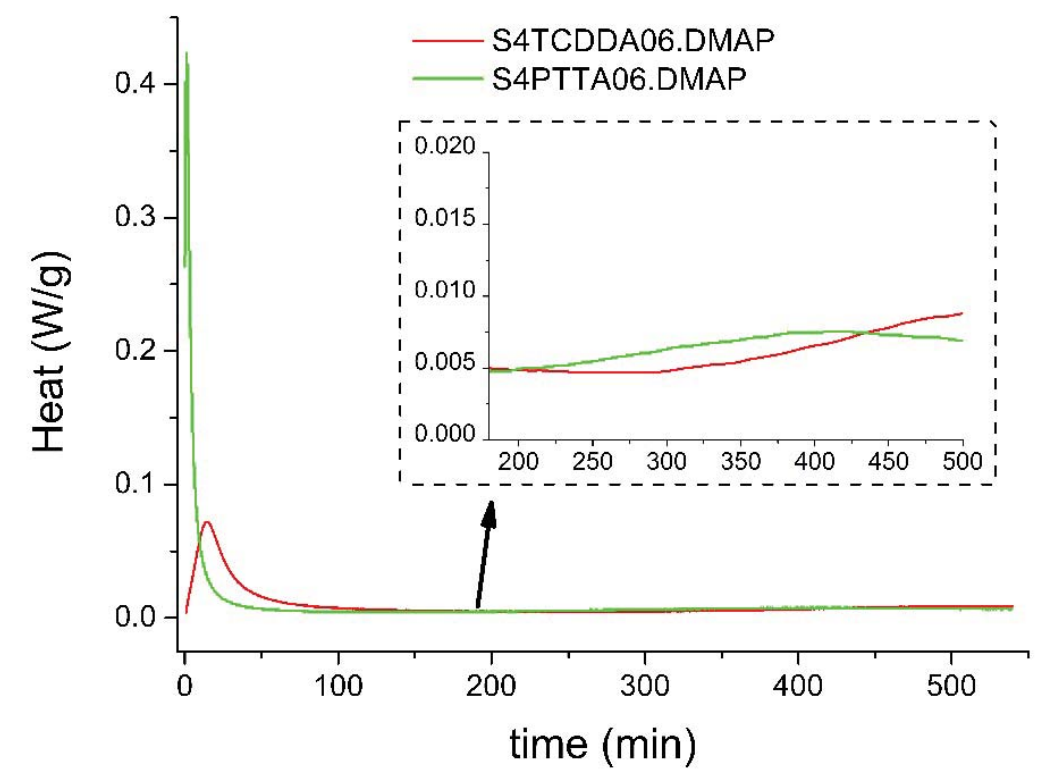

Figure 6. DSC isothermal analysis at $30^{\circ} \mathrm{C}$ of S4TCDDA06.DMAP and S4PTTA.DMAP.

Table 4 shows some important parameters of the dual formulations under investigation. $\Delta \mathrm{H}_{1}$ values measured after the $1^{\text {st }}$ stage at $30^{\circ} \mathrm{C}$ are about $10 \mathrm{~kJ} / \mathrm{eq}$ higher than the one measured for thiol-acrylate pure formulations. One could hypothesize this is caused by the occurrence of thiol-epoxy reaction to some little extent, but such discrepancy is more probably ascribed to the uncertainty associated with the determination of reaction heat from the DSC analysis of the neat thiol-acrylate formulations. Assuming that they are affected by the same experimental error of the pure formulations, these higher values could be ascribed to a fraction of thiol, which starts to react with the epoxy at such low reaction rate that it is not visible in the DSC thermograms. This will be later detected and discussed by FTIR analysis. The intermediate $T_{\mathrm{g} 1}$ s were very similar to the predicted using the Fox equation, after completion of the thiol-acrylate reaction and before starting the thiol-epoxy reaction. With regards to the final $\mathrm{T}_{\mathrm{g} 2}$, S4PTTA06 shows a $\mathrm{T}_{\mathrm{g} 2}=39^{\circ} \mathrm{C}$ that is quite higher than $30^{\circ} \mathrm{C}$ reached with the $54 \mathrm{TCDDA06}$. The produced values are higher than those predicted by the Fox equation, but within experimental error. In addition, the Fox equation assumes ideal mixture between the thiol-epoxy and thiol-acrylate networks and is not able to consider other effects such as any structural effects or other secondary interactions between the thiol-acrylate and epoxy networks, as for example, hydrogen bonding 
Table 4. Isothermal reaction heats, $\Delta \mathrm{H}_{1}$ (Stage 1,200 min at $30^{\circ} \mathrm{C}$ ), $\Delta \mathrm{H}_{2}$ (Stage $2,120 \mathrm{~min}$ at $60^{\circ} \mathrm{C}$ ); $\mathrm{T}_{\mathrm{g} 1}$ and $\mathrm{T}_{\mathrm{g} 2}$ obtained experimentally (using $0.05 \mathrm{phr}$ of DMAP) measured, respectively after $200 \mathrm{~min}$ at $30^{\circ} \mathrm{C}$ and dynamic curing from $30-180^{\circ} \mathrm{C}\left(10^{\circ} \mathrm{C} / \mathrm{min}\right) ; \mathrm{T}_{\mathrm{g} 1, \text { th }}$ an $\mathrm{T}_{\mathrm{g} 2, \text { th }}$ obtained by theoretical prediction.

\begin{tabular}{|c|c|c|c|c|c|c|c|c|}
\hline Formulation & $\begin{array}{l}\Delta \mathrm{H}_{1} \\
(\mathrm{~J} / \mathrm{g})\end{array}$ & $\Delta \mathrm{H}_{1}(\mathrm{~kJ} / \mathrm{eq})$ & $\Delta \mathrm{H}_{2}(\mathrm{~J} / \mathrm{g})$ & $\Delta \mathrm{H}_{2}(\mathrm{KJ} / \mathrm{eq})$ & $\mathrm{T}_{\mathrm{g} 1}\left({ }^{\circ} \mathrm{C}\right)$ & $\mathrm{T}_{\mathrm{g} 2}\left({ }^{\circ} \mathrm{C}\right)$ & $\mathrm{T}_{\mathrm{g} 2, \mathrm{th}}\left({ }^{\circ} \mathrm{C}\right)$ & $\mathrm{T}_{\mathrm{g} 2, \mathrm{th}}\left({ }^{\circ} \mathrm{C}\right)$ \\
\hline S4TCDDA06.1MI & 55 & 56 & 179 & 129 & \multirow{2}{*}{-5} & \multirow{2}{*}{30} & \multirow{2}{*}{-9} & \multirow{2}{*}{28} \\
\hline S4TCDDA06.DMAP & 121 & 58 & 168 & 121 & & & & \\
\hline S4PTTA06.1MI & 126 & 52 & 182 & 114 & \multirow{2}{*}{-10} & \multirow{2}{*}{39} & \multirow{2}{*}{-12} & \multirow{2}{*}{31} \\
\hline S4PTTA06.DMAP & 140 & 58 & 164 & 102 & & & & \\
\hline
\end{tabular}

The influence of the curing temperature was also investigated. Figure 7 compares two curing process performed at $30^{\circ} \mathrm{C}$ and $60^{\circ} \mathrm{C}$ for S4TCDDA.DMAP. In this case, the second curing stage also comes to the end in a reasonable time. The heat released of $121 \mathrm{~J} / \mathrm{eq}$, similar to the value reported for similar epoxy-thiol reaction, is a further proof that confirms the completion of the $2^{\text {nd }}$ stage. Unfortunately, the curing at $60^{\circ} \mathrm{C}$ causes an important overlapping of the two reactions which undermines the sequentiality of the process. This could be expected taking into account the previous kinetics analysis of neat thiol-epoxy and thiolacrylate systems.

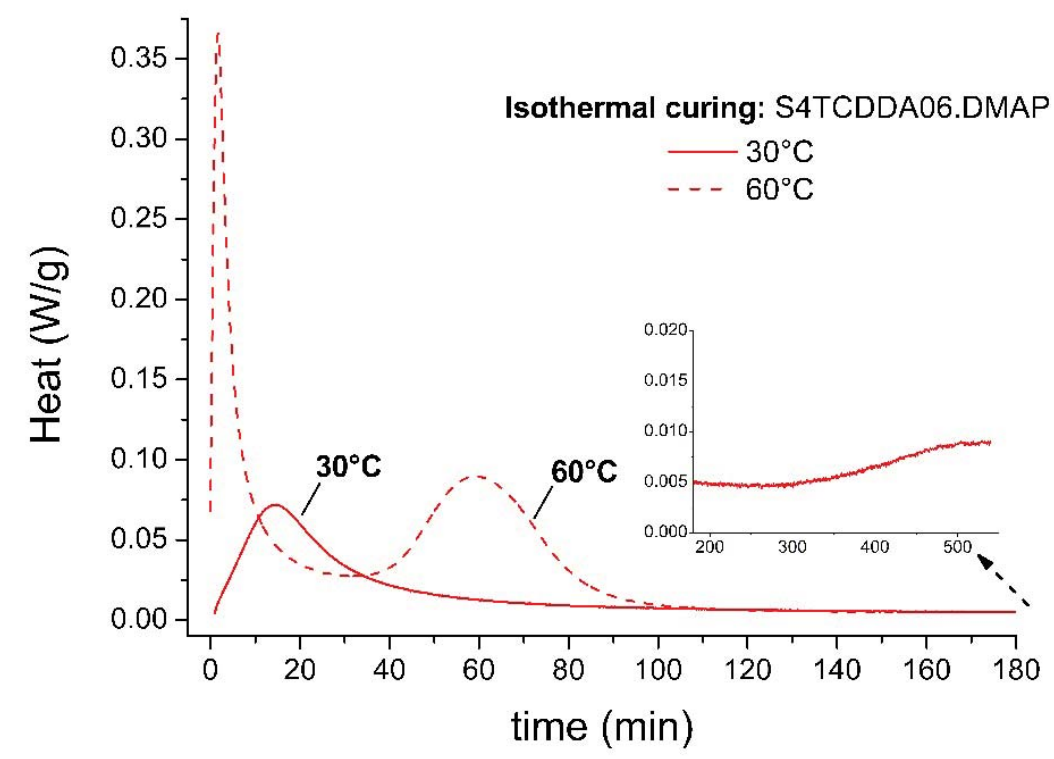

Figure 7. Comparison between isothermal curing in DSC at $30^{\circ} \mathrm{C}$ and $60^{\circ} \mathrm{C}$ of $S 4 T C D D A 06$.

DSC results show that the low-temperature curing seems to ensure a sequential curing process with intermediate materials stable enough to manipulate before the second curing stage, which can be performed at higher temperature to accelerate it and ensure complete cure. However, the results of the calorimetric 
analysis are not precise enough in order to clarify whether the two polymerization processes are strictly sequential or else there is some overlapping between them, and what happens during the stability period between the reaction peaks detected with DSC. For this purpose, the curing process at $30^{\circ} \mathrm{C}$ of S4TCDDA06 formulations with 0.05 phr DMAP and 0.25 phr $1 \mathrm{MI}$ were monitored by FTIR.

Figure 8 shows the evolution of the FTIR spectra during the curing processes using $1 \mathrm{MI}$ as initiator. We have highlighted the evolution of the characteristic peak of acrylate $\left(810,1410\right.$ and $\left.1630 \mathrm{~cm}^{-1}\right)$, thiol $\left(2570 \mathrm{~cm}^{-1}\right)$, hydroxyl $\left(3600 \mathrm{~cm}^{-1}\right)$ and epoxy $\left(860\right.$ and $\left.915 \mathrm{~cm}^{-1}\right)$ groups. The acrylate conversion $\left(810 \mathrm{~cm}^{-1}\right)$ and the epoxy conversion $\left(860 \mathrm{~cm}^{-1}\right)$ are plotted in Figure 9 for both $1 \mathrm{MI}$ and DMAP.

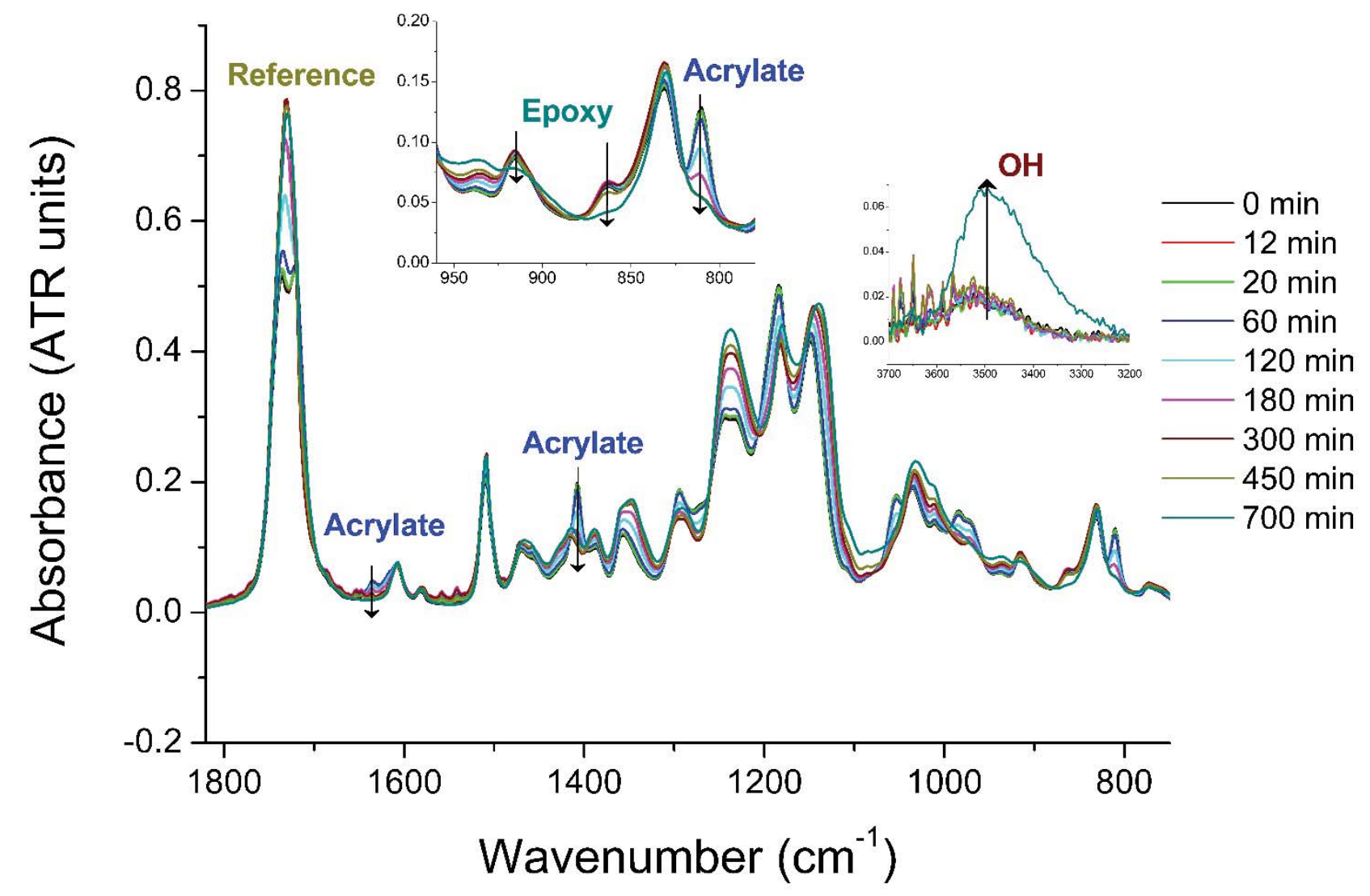

Figure 8. Evolution of FTIR spectra at $30^{\circ} \mathrm{C}$ for S4TCDDA06.1MImonitored during $700 \mathrm{~min}$. Insets show the evolution of specific peaks related to $\mathrm{OH}$ formation and consumption of acrylate, epoxy and thiol groups. 

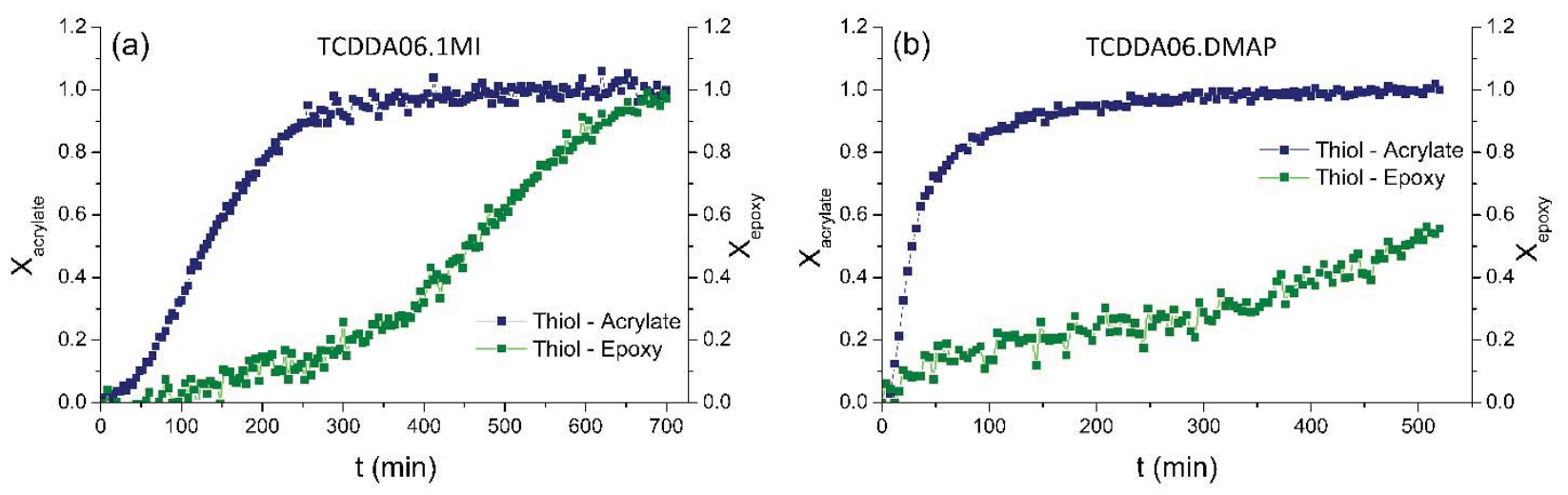

Figure 9. FTIR acrylate conversion - time plot and FTIR epoxy conversion - time plot for S4TCDDA06.1MI (a) and

\section{S4TCDDA06.DMAP (b).}

Figure 8 and Figure 9.a show that the reaction of acrylate groups with $1 \mathrm{Ml}$ is fast and complete in about 300 minutes. All the acrylate signals in Figure 8 show a similar evolution. The acrylate conversion profiles in Figure 9 evidence the faster reactivity of S4TCDDA06 with DMAP than with 1MI, in agreement with the calorimetric results. A low rate activation step is visible in the conversion plot of S4TCDDA.1MI. Figure 8 shows that there is some evolution of the $915 \mathrm{~cm}^{-1}$ signal, typically used in the analysis of epoxy systems [33], along with the reaction of acrylate groups, suggesting that thiol-epoxy reaction starts together with the thiol-acrylate, although at a very low rate. However, the small size of the peak and the presence of overlapping neighbouring signals make the analysis of this signal quite uncertain. In addition, the observed changes around $915 \mathrm{~cm}^{-1}$ in the first part of the process might be ascribed to the thiol-acrylate reaction instead. We have analyzed the evolution of the signal at $915 \mathrm{~cm}^{-1}$ (results not shown) and have observed a change in the absorbance at 915 $\mathrm{cm}^{-1}$ peak after $400 \mathrm{~min}$ for S4TCDDA06.1MI, once the thiol-acrylate reaction is almost complete, indicating the onset of the thiol-epoxy reaction. In order to clarify this, we have analysed other signals that can be associated with the thiol-epoxy reaction. Figure 8 shows that the small peak at $860 \mathrm{~cm}^{-1}$ remains virtually unaltered during the thiol-acrylate reaction, showing only appreciable changes at $450 \mathrm{~min}$. The calculation of the conversion of epoxy groups, making use of the peak at $860 \mathrm{~cm}^{-1}$, represented also in Figure 9.a, confirms that thiol-epoxy reaction is only relevant after $400 \mathrm{~min}$. The conversion plots suggest there might be some conversion of epoxy groups during the thiol-acrylate reaction, but this could be an artifact resulting from the small size of the peak, the mathematical deconvolution procedure needed to separate the contribution of the different peaks in that region of the spectrum (see inset in Figure 8) and the changes taking place in neighbouring signals because of the thiol-acrylate reaction (i.e. disappearance of the peak at $810 \mathrm{~cm}^{-1}$ ). Moreover, Figure 8 shows that, setting aside baseline noise, no relevant changes take place in the $\mathrm{OH}$ peak at $3600 \mathrm{~cm}^{-1}$ during the thiol-acrylate reaction, indicating that the concentration of $\mathrm{OH}$ groups remains almost constant and therefore the thiol-epoxy reaction is not taking place. Relevant changes in the $\mathrm{OH}$ band at $3600 \mathrm{~cm}^{-1}$, caused by the thiol-epoxy reaction, are only detected after $400 \mathrm{~min}$ for the formulation with $1 \mathrm{MI}$. The evolution of thiol group peak at $2570 \mathrm{~cm}^{-1}$ was also investigated (Figure 10). Despite the 
experimental uncertainty caused by the small size of the peak and experimental noise, thiol conversion along time shows a certain stability step between 200 and 400 min, confirming that thiol-acrylate and thiol-epoxy reactions take place in an almost sequential way. Figure 9.b shows that there is some apparent conversion of epoxy groups during the thiol-acrylate reaction for S4TCDDA06.DMAP, but is probably an artifact coming from the mathematical procedure to determine the individual area of the signal at $860 \mathrm{~cm}^{-1}$ and therefore the conversion. The thiol-epoxy reaction was not observed to take place quantitatively because the FTIR analysis was not extended long enough.
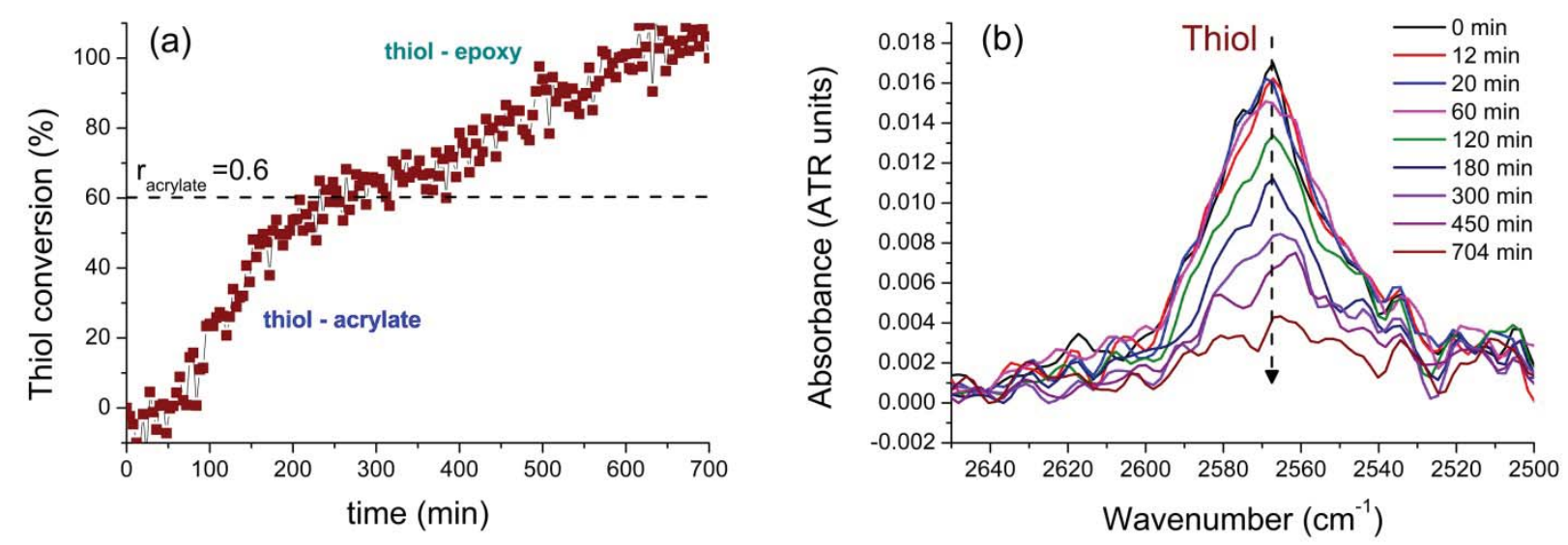

Figure 10. FTIR thiol conversion along time (a); FTIR spectra of the thiol peek at $2600 \mathrm{~cm}^{-1}$ (b).

These findings are in line with the results obtained by DSC confirming that, even if the system is not exactly sequential, the low reaction rate of the second stage shall ensure that the process can be accepted as sequential. In the case of the dual system with $1 \mathrm{MI}$, it is confirmed that one can find an extended period of time (250 - $400 \mathrm{~min}$ ) in which the acrylate reaction is almost complete, and the thiol-epoxy reaction is not yet started or taking place at a very slow rate, during which the properties should not change appreciably. This should allow for some manipulation of this intermediate material at room temperature before quantitative activation of the second curing reaction and completion of the crosslinking process.

\subsection{Potential applications of the developed materials}

In this last section, the potential application of these materials is discussed. First of all, a curing procedure of the selected formulation in the oven has to be optimized. In the previous section, we have explained that a curing temperature close to $T_{\text {room }}$ lead to a good separation between the two reactions. The problem is that at this temperature the thiol-epoxy is very slow and, according to the values of $\mathrm{T}_{\mathrm{g}}$ reported in Table 4, vitrification might take place, leading to incomplete cure. Taking in consideration these results we decided to divide the process in two temperature steps (Figure 11): the first curing step at $30^{\circ} \mathrm{C}$ to promote the thiolacrylate and, after that, raising the temperature to $60^{\circ} \mathrm{C}$ to allow the complete curing of thiol-epoxy in a 
reasonable time. As already discussed, the inhibition of the second reaction at room temperature will give us enough time to manipulate the intermediate materials out of the oven to get the desired shape or to adhere to other materials.

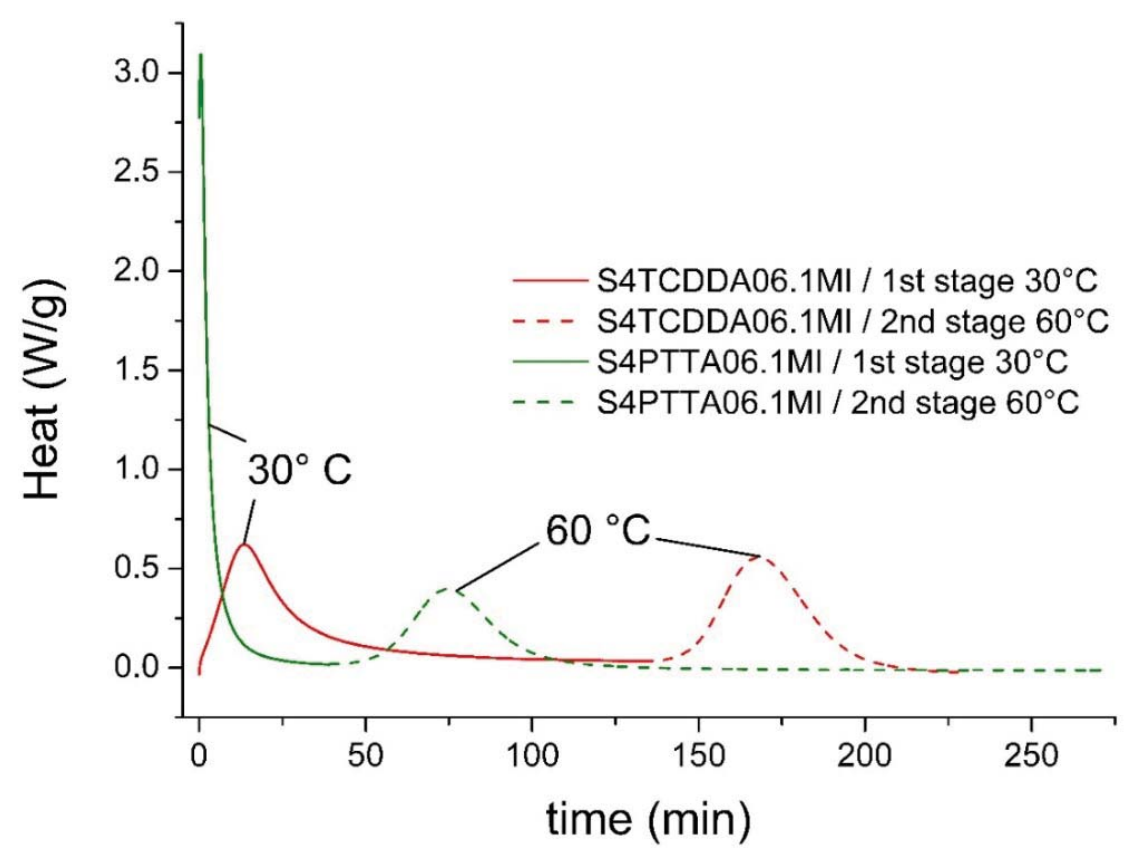

Figure 11. DSC two-isothermal-step curing of S4TCDDA06 and S4PTTA06 with $0.25 \mathrm{phr}$ of $1 \mathrm{MI}$ : First stage at $30^{\circ} \mathrm{C}$ (solid line); second stage at $60^{\circ} \mathrm{C}$ (dot-dot line).

We performed some curing tests in the oven to identify the time required for each stage. After some tests, the adequate procedure was set as follow: 2 hours at $30^{\circ} \mathrm{C}$ for (1st stage); 3 hours at $60^{\circ} \mathrm{C}$ (2nd stage) followed by 1 hours at $80^{\circ} \mathrm{C}$ to ensure completion of the curing process. The second stage could be replaced with 1-2 hours at $80^{\circ} \mathrm{C}$ to shorten the duration of the process.

In Figure 12 some examples of conformation and processing of complex shapes are shown using S4TCDDA06.1MI formulations. As expected, the $r_{\text {acrylate }}=0.6$ gives gelled and conformable intermediate materials. Starting from the intermediate shape, obtained with standard open moulds, we were able to transform the specimen into complex shapes that were finally fixed through the second curing stage. We were also able to obtain a rod-like specimen using a silicon tube as moulding part. After the first curing stage the rod-shaped specimen was extracted, and it was rolled up around a teflonated cylinder to achieve a springlike shape. After the second curing step the final spring was obtained. Dog-bone specimens were also obtained by die-cutting of intermediate materials sheets. Intermediate materials samples can also be cut in complex shape simply using cutters or scissors. Damaged samples also demonstrate self-repairing properties during the second curing stage. All these examples prove the high versatility of this material processing which makes them potentially suitable for numerous applications. 


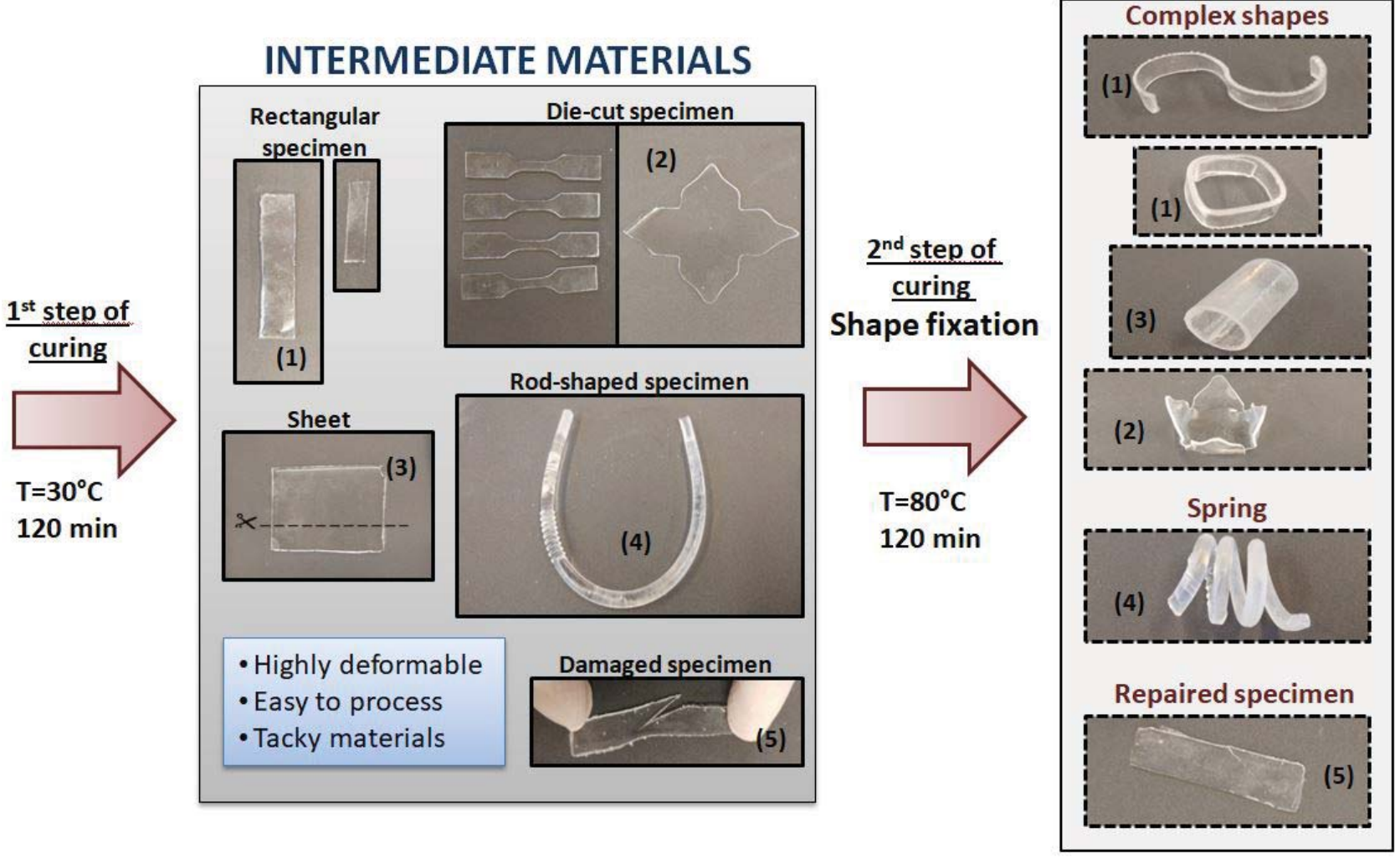

Figure 12. Examples of complex shapes obtained by intermediate material processing followed by fixation of the final material shapes through second curing stage.

Finally, the intermediate materials were tested as adhesive bonding (Figure 13). We tested two different configurations: external joining configuration suitable to connect pipes and internal joining that can be used for solid rods. First, the uncured formulation was poured into a mould and cured at $30^{\circ}$ for $90 \mathrm{~min}$. We decided to reduce the curing time to obtain intermediate materials with enhanced adhesive properties. Once an intermediate sheet was obtained, an especially designed die cutting mould was used to obtain a strip (Figure 13.a), while a circular shape (Figure 13.b) was cut from another sheet. The circular sample was placed between two metal rods. An unspecified weight was placed on the top, to ensure the adhesion between metal and polymeric surfaces, and the assembly was put in the oven for the second curing stage. The strip was used to join two pipe pieces. Thanks to the high deformability, the material was wrapped around the pipes and an adhesive Teflon strip was rolled onto it to maintain contact during the second curing stage. When the curing process is over, almost perfect adhesion was achieved in both configurations, the two pieces had adhered to each other perfectly and they could not be separated by any hand manipulation. Since promising results was obtained with this visual evaluation, we propose to go ahead with a more precise characterization of this behaviour. The effect of $r_{\text {acrylate }}$ and $1^{\text {st }}$ stage curing time on the resistance of the junction will be evaluated in future works. 


\section{PROCESSING:}

(1) 1 st curing : $\mathrm{T}=30^{\circ} \mathrm{C} 90 \mathrm{~min}$ (3) 2nd curing: $\mathrm{T}=80^{\circ} \mathrm{C} 120 \mathrm{~min}$

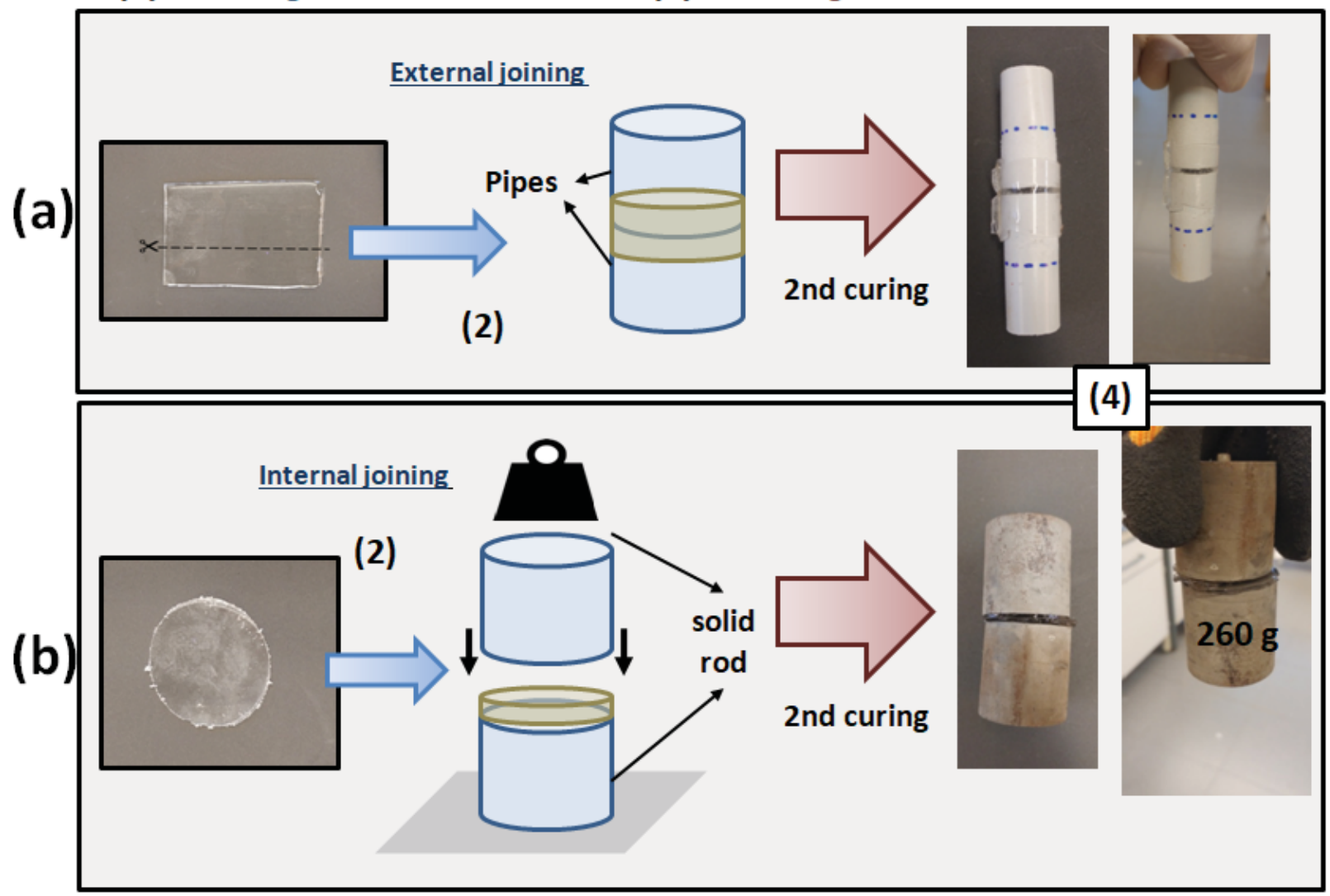

Figure 13. Illustration of the adhesive bonding tests: (a) Intermediate material strip used as external bonding of two pipe pieces; (b) circular shaped specimen used to bond two metal rods (all the surfaces in contact with the adhesive were pre-treated with abrasive paper to improve the adhesion).

\section{CONCLUSIONS}

In this work, we have studied the sequential character of dual-curing systems based on the combination of thiol-acrylate and thiol-epoxy formulations, using basic/nucleophilic tertiary amines as thermal catalysts. The curing process of the pure acrylate-thiol and epoxy-thiol formulations and dual systems has been studied using differential scanning calorimetry and infrared spectroscopy.

The analysis of the curing kinetics of pure thiol-acrylate and thiol-epoxy systems revealed completely different kinetic behaviour due to: (1) the faster kinetics of the nucleophile-mediated thio-Michael addition to acrylates, (2) the autocatalytic character of the thiol-epoxy reaction, with a long induction period due to slow initiation kinetics and (3) the weak temperature dependence of the thiol-acrylate reaction in comparison with the thiol-epoxy reaction. All these factors pointed out at the possibility of defining dualcuring formulations with an almost sequential character. The preliminary analysis also allowed us to identify 
PTTA and DMAP as the best combination of acrylate and catalyst to enhance the separation between the thiol-acrylate and thiol-epoxy reactions.

Calorimetric results demonstrated that the curing process takes place in well-defined curing stages with enough stability of the intermediate materials at room temperature to enable safe handling and manipulation before the final application and triggering of the second curing stage. The dilution of the epoxy monomer in the dual-curing formulation enhanced the separation between curing stages due to the further slowing down of the thiol-epoxy reaction. The evolution of the characteristic signals of acrylate, epoxy, thiol and hydroxyl groups, in the mid-infrared spectrum, confirmed the almost sequential character of the dualcuring system, with little or no overlapping at all between the thiol-acrylate and thiol-epoxy reactions. Safe curing schedules, ensuring a sequential curing process, could thus be defined: 2 hours at $30^{\circ} \mathrm{C}$ for the first curing stage, followed by 2 hours at a higher temperature of $60-80^{\circ} \mathrm{C}$.

The dual-curing systems based on ternary acrylate-epoxy-thiol formulations can produce a range of intermediate and final materials with highly tailorable properties depending on the monomer structure and feed ratio. We were able to easily process the intermediate materials, which were conformed or die-cut into complex shapes. The obtained shapes were transformed and fixed by the second curing stage and different rigid shapes were finally obtained. Furthermore, the viability of intermediate materials to act as adhesive bonding were successfully tested. Two different bonding configurations were tested: an external joining of pipes and an internal joining of metal rods. Optimum results were obtained with both configurations proving the high potentiality of these materials in this field of application.

\section{AKNOWLEDGMENTS}

The authors would like to thank MINECO (MAT2017-82849-C2-1-R and 2-R) and GENCAT (2017-SGR-77 and Serra Húnter programme) for the financial support.

\section{References}

[1] J.P. Pascault, H. Sautereau, J. Verdu, R.J.J.Williams, Thermosetting Polymers, first ed., New York, 2002.

[2] A. Lendlein, Progress in actively moving polymers, J. Material. Chem., 20 (2010) 3332-3334. DOI: 10.1039/C004361N. https://doi.org/10.1039/C004361N.

[3] B.D. Mather, K. Viswanathan, K.M. Miller, T.E. Long, Michael addition reactions in macromolecular design for emerging technologies, Prog. Polym. Sci., $31 \quad$ (2006) 487-531. https://doi.org/10.1016/j.progpolymsci.2006.03.001 DOI: 10.1016/200603001.

[4] X. Ramis, X. Fernández-Francos, S. De la Flor, A. Serra, Click-based dual-curing thermosets and their applications, in: G. Quo (Eds.), Thermosets Structure, Properties, and Applications, Elsevier, 2017, pp. 511577. 
[5] C.E. Hoyle, A.B. Lowe, C.N. Bowman, Thiol-click chemistry: a multifaceted toolbox for small molecule and polymer synthesis, Chem. Soc. Rev.,39 (2010) 1355-1387. DOI:10.1039/B901979K.

[6] J.E. Moses, A.D. Moorhouse, The growing applications of click chemistry, Chem. Soc. Rev., 36 (2007) 12491262. DOI: 10.1039/B613014N.

[7] W.H. Binder, R. Sachsenhofer, 'Click' Chemistry in Polymer and Materials Science, Macromol. Rapid. Commun., 28 (2007) 15-54. https://doi.org/10.1002/marc.200600625 DOI: 10.1002/200600525.

[8] S. De, A. Khan, Efficient synthesis of multifunctional polymers via thiol-epoxy "click"' chemistry, Chem. Commun., 48 (2012) 3130-3132. DOI: 10.1039/C2CC30434A.

[9] A.B. Lowe, C.E. Hoyle, C.N. Bowman, Thiol-Yne Click Chemistry: A Powerful and Versatile Methodology for Materials Synthesis, J. Mater. Chem., 20 (2010) 4745-4750. DOI: 10.1039/B917102A.

[10] K. Jin, J.M. Torkelson, Kinetics of Multifunctional Thiol-Epoxy Click Reactions Studied by Differential Scanning Calorimetry: Effects of Catalysis and Functionality, Polymers, 81 (2015) 70-78. https://doi.org/10.1016/j.polymer.2015.10.068 DOI: 10.1016/201510068.

[11] Y. Jian, Y. He, Y. Sun, H. Yang, W. Yang, J. Nie, Thiol-epoxy/thiol-acrylate hybrid materials synthesized by photo-polymerization, J. Mater. Chem. C, 1 (2013) 4481-4489. DOI: 10.1039/C3TC30360H.

[12] A. Belmonte, D. Guzmán, X. Fernández-Franco, S. De la Flor, Effect of the Network Structure and Programming Temperature on the Shape-Memory Response of Thiol-Epoxy "Click" Systems, Polymers, 7 (2015) 2146-2164. http://dx.doi.org/10.3390/polym7101505 DOI: 10.3390/7101505.

[13] A. Belmonte, C. Russo, V. Ambrogi, X. Fernández-Francos, S. De la Flor, Epoxy-Based Shape-Memory Actuators Obtained via Dual-Curing of Off-Stoichiometric "Thiol-Epoxy" Mixtures, Polymers, 9 (2017) 113. http://dx.doi.org/10.3390/polym9030113 DOI: 10.3390/9030113.

[14] A. Belmonte, G.C. Lama, G. Gentile, X. Fernández-Francos, S. De la Flor, P. Cerrutti, V. Ambrogi, Synthesis and Characterization of Liquid-Crystalline Networks: Toward Autonomous Shape-Memory Actuation, J. Phys. Chem. C, 121 (2017) 22403-22414. http://dx.doi.org/10.1021/acs.jpcc.7b04610 DOI: 10.1021/7B04610.

[15] A. Belmonte, G.C. Lama, G. Gentile, P. Cerruti, V. Ambrogi, X. Fernández-Francos, S. De la Flor; Thermallytriggered free-standing shape-memory actuators; Eur. Polym. J., 2017,97,241-252. https://doi.org/10.1016/j.eurpolymj.2017.10.006 DOI: 10.1016/201710006.

[16] A.O. Konuray, X. Fernández-Francos, X. Ramis; Curing kinetics and characterization of dual-curable thiolacrylate-epoxy thermosets with latent reactivity; React. Funct. Polym., 2018, 122, 60-67. https://doi.org/10.1016/i.reactfunctpolym.2017.11.010 DOI: 10.1016/201711010.

[17] K. Jin, N. Wilmot, W.H. Heath, J.M. Torkelson; Phase-Separated Thiol-Epoxy-Acrylate Hybrid Polymer Networks with Controlled Cross-Link Density Synthesized by Simultaneous Thiol-Acrylate and Thiol-Epoxy Click Reactions; Macromolecules, 2016, 49, 4115-4123. http://dx.doi.org/10.1021/acs.macromol.6b00141 DOI: 10.1021/6B001141. 
[18] G. Gonzalez, X. Fernandez-Francos, A. Serra, M. Sangermano, X. Ramis; Environmenta Ily-friendly processing of thermosets by two-stage sequential aza-Michael addition and free-radical polymerization of amine-acrylate mixtures; Polym. Chem. 2015, 6, 6987-6997. https://doi.org/10.1039/C5PY00906E DOI: 10.1039/C5PY00906E.

[19] S. Paz-Abuin, A. Lopez-Quintela, M. Varela, M. Pazos-Pellin, P. Prendes; Method for determination of the ratio of rate constants, secondary to primary amine, in epoxy-amine systems; Polymers, 1997, 38, 3117-3120. https://doi.org/10.1016/S0032-3861(96)01093-2 DOI: 10.1016/S0032-3861(96)01093-2.

[20] A.O. Konuray, X. Fernández-Francos, X. Ramis; Analysis of the reaction mechanism of the thiol-epoxy addition initiated by nucleophilic tertiary amines; Polym. Chem., 2017, 8, 5934-5947. https://doi.org/10.1039/C7PY01263B DOI: 10.1039/C7PY01263B.

[21] R. Thomas, C. Sinturel, J. Pionteck, H. Puliyalil, S. Thomas; In-situ cure and cure kinetic analysis of a liquid rubber modified epoxy resin; Ind. Eng. Chem. Res., 2012, 51, 12178-12191 https://dx.doi.org/10.1021/ie2029927 DOI: 10.1021/ie2029927.

[22] X. Fernández-Francos, A.O. Konuray, A. Belmonte; Sequential curing of off-stoichiometric thiol-epoxy thermosets with a custom-tailored structure; Polym. Chem., 2016, 7, 2280-2290. https://doi.org/10.1039/C6PY00099A DOI: 10.1039/C6PY00099A .

[23] J.W. Chan, C.E. Hoyle, A.B. Lowe, M. Bowman; Nucleophile-Initiated Thiol-Michael Reactions: Effect of Organo catalyst, Thiol, and Ene; Macromolecules, 2010, 43, 6381-6388. DOI: 10.1021/ma101069c.

[24] D. Guzmán, X. Ramis, X. Fernández-Francos, A. Serra; New catalysts for diglycidyl ether of bisphenol A curing based on thiol-epoxy click reaction; Eur. Polym. J., 2014, 59, 377-386. https://doi.org/10.1016/j.eurpolymj.2014.08.001 DOI: 10.1016/201408001.

[25] B.A. Rozenberg; Kinetics, thermodynamics and mechanism of reactions of epoxy oligomers with amines; Adv. Polym. Sci., 1986, 75, 113-165. https://doi.org/10.1007/BFb0017916 DOI: 10.1007/BFb0017916.

[26] X. Fernández-Francos; Theoretical modelling of the effect of proton donors and regeneration reactions in the network build-up of epoxy thermosets using tertiary amines as initiators; Eur. Polym. J., 2014, 55, 3547. https://doi.org/10.1016/j.eurpolymj.2014.03.022 DOI: 10.1016/201403022.

[27] J.A. Carioscia, J.W. Stansbury, C.N. Bowman; Evaluation and control of thiol-ene/thiol-epoxy hybrid networks; Polymer, 2007, 48, 1526-1532. https://doi.org/10.1016/j.polymer.2007.01.044 DOI: 10.1016/200701044.

[28] L. Matějka, S. Pokorný, K. Dušek, Acid curing of epoxy resins. A comparison between the polymerization of diepoxide-diacid and monoepoxide-cyclic anhydride systems, Die Makromolekulare Chemie, 1985, 186, 2025-2036.

[29] M.S. Heise, G.C. Martin, J.T. Gotro, Characterization of imidazole-cured epoxy-phenol resins, J. Appl. Polym. Sci., 1991, 42, 1557-1566 
[30] S. Vyazovkin, N. Sbirrazzuoli; Isoconversional kinetic analysis of thermally stimulated processes in polymers; Macromol. Rapid Commun., 2006, 27, 1515-1532. https://doi.org/10.1002/marc.200600404 DOI: 10.1002/200600404.

[31] M.J. Starink; The determination of activation energy from linear heating rate experiments: a comparison of the accuracy of isoconversion methods; Thermochim. Acta., 2003, 404, 163-176. https://doi.org/10.1016/S0040-6031(03)00144-8 DOI: 10.1016/S0040-6031(03)00144-8.

[32] X. Fernandez, X. Ramis, J.M. Salla; Cationic copolymerization of cycloaliphatic epoxy resin with anspirobislactone with lanthanum triflate as initiator: Kinetics of the curing process; Thermochim. Acta., 2005, 438, 144-154. https://doi.org/10.1016/j.tca.2005.07.012 DOI: 10.1016/j.tca.2005.07.012.

[33] X. Fernandez-Francos, W.D. Cook, A. Serra, X. Ramis, G.G. Liang and J.M. Salla; Crosslinking of mixtures of DGEBA with 1,6-dioxaspiro[4,4]nonan-2,7-dione initiated by tertiary amines. Part IV. Effect of hydroxyl groups on initiation and curing kinetics; Polymer, 2010, 51, 26-34 https://doi.org/10.1016/j.polymer.2009.11.013 DOI: 10.1016/j.polymer.2009.11.013. 